\title{
Small-Scale Spray Releases: Orifice Plugging Test Results
}

\author{
LA Mahoney ML Kimura \\ PA Gauglitz DE Kurath \\ J Blanchard
}

September 2012

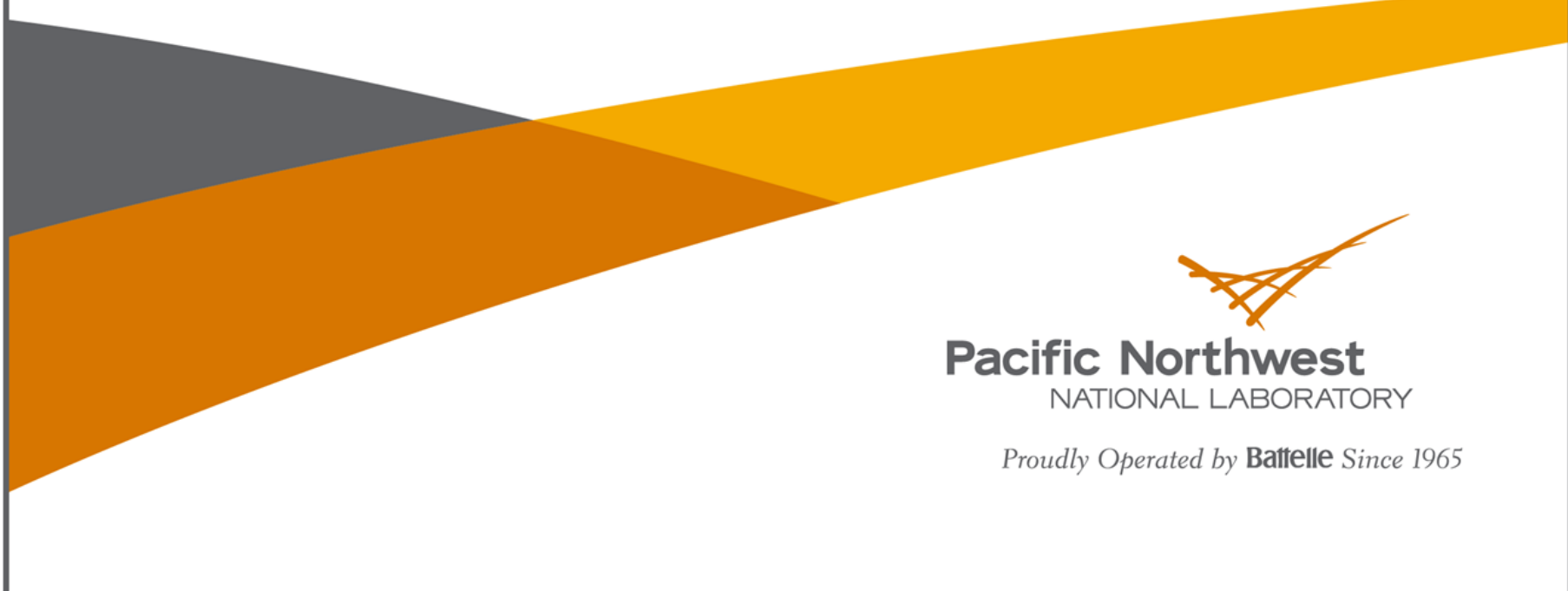




\title{
DISCLAIMER
}

This report was prepared as an account of work sponsored by an agency of the United States Government. Neither the United States Government nor any agency thereof, nor Battelle Memorial Institute, nor any of their employees, makes any warranty, express or implied, or assumes any legal liability or responsibility for the accuracy, completeness, or usefulness of any information, apparatus, product, or process disclosed, or represents that its use would not infringe privately owned rights. Reference herein to any specific commercial product, process, or service by trade name, trademark, manufacturer, or otherwise does not necessarily constitute or imply its endorsement, recommendation, or favoring by the United States Government or any agency thereof, or Battelle Memorial Institute. The views and opinions of authors expressed herein do not necessarily state or reflect those of the United States Government or any agency thereof.

\author{
PACIFIC NORTHWEST NATIONAL LABORATORY \\ operated by \\ BATTELLE \\ for the \\ UNITED STATES DEPARTMENT OF ENERGY \\ under Contract DE-AC05-76RL01830
}

Printed in the United States of America

Available to DOE and DOE contractors from the

Office of Scientific and Technical Information,

P.O. Box 62, Oak Ridge, TN 37831-0062;

ph: (865) 576-8401

fax: $(865) 576-5728$

email: reports@adonis.osti.gov

\author{
Available to the public from the National Technical Information Service \\ 5301 Shawnee Rd., Alexandria, VA 22312 \\ ph: (800) 553-NTIS (6847) \\ email: orders@ntis.gov <http://www.ntis.gov/about/form.aspx> \\ Online ordering: http://www.ntis.gov
}

This document was printed on recycled paper. 


\title{
Small-Scale Spray Releases: Orifice Plugging Test Results
}

\author{
LA Mahoney \\ ML Kimura \\ PA Gauglitz \\ DE Kurath \\ J Blanchard
}

September 2012

Test Specification: None

Work Authorization: WA42AM01

Test Plan: TP-WTPSP-031, Rev. 0.2

Test Exceptions: None

Prepared for

the U.S. Department of Energy

under Contract DE AC05 76RL01830

Pacific Northwest National Laboratory

Richland, Washington 99352 



\section{Completeness of Testing}

This report describes the results of work and testing specified by Test Plan TP-WTPSP-031, Rev. 0.2. The work followed the quality assurance requirements outlined in the test plan. The descriptions provided in this report are an accurate account of both the conduct of the work and the data collected. Test plan results are reported. Also reported are any unusual or anomalous occurrences that are different from expected results. The test results and this report have been reviewed and verified.

Approved:

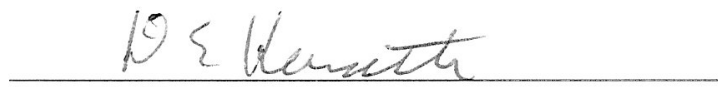

Dean E. Kurath, Manager WTP R\&T Support Project

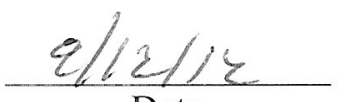

Date 



\section{Testing Summary}

One of the events postulated in the hazard analysis at the Waste Treatment and Immobilization Plant (WTP) and other U.S. Department of Energy (DOE) nuclear facilities, is a breach in process piping that produces aerosols with droplet sizes in the respirable range. The current approach for predicting the size and concentration of aerosols produced in a spray leak involves extrapolating from correlations published in the literature. These correlations are based on results obtained from small engineered spray nozzles using pure liquids with Newtonian fluid behavior. The narrow ranges of physical properties on which the correlations are based do not cover the wide range of slurries and viscous materials present in the WTP and across processing facilities in the DOE complex.

Two key technical areas were identified where testing results were needed to improve the technical basis by reducing the uncertainty introduced by extrapolating existing literature results. The first technical need was to quantify the role of slurry particles in small breaches in which the slurry particles may plug and result in substantially reduced, or even negligible, respirable fraction formed by high-pressure sprays. The second technical need was to determine the aerosol droplet size distribution and volume from prototypic breaches and fluids, specifically including sprays from larger breaches with slurries where data from the literature are largely absent.

To address these technical areas, small- and large-scale test stands were constructed and operated with simulants to determine the aerosol release fractions and aerosol generation rates from a range of breach sizes and geometries. The properties of the simulants represented the range of properties expected in the WTP process streams and included water, sodium salt solutions, slurries containing boehmite or gibbsite, and a hazardous chemical simulant. The effect of anti-foam agents (AFA) was assessed with most of the simulants. Orifices included round holes and rectangular slots. Much of the testing was conducted at pressures of 200 and $380 \mathrm{psi}$, but some tests were conducted at $100 \mathrm{psi}$. Testing the largest postulated breaches was deemed impractical because of the much larger flow rates and equipment that would be required.

The purpose of the study described in this report is to provide experimental data for the first key technical area, potential plugging of small breaches, by performing small-scale tests with a range of orifice sizes and orientations representative of the WTP conditions. The simulants used were chosen to represent the range of process stream properties in the WTP. Testing conducted after the plugging tests in the small- and large-scale test stands addresses the second key technical area, aerosol generation. The results of the small-scale aerosol generation tests are included in Mahoney et al. (2012). The area of spray generation from large breaches is covered by large-scale testing in Schonewill et al. (2012).

\section{S.1 Objective}

Table S.1 provides the objectives that apply to the small-scale plugging tests. Other objectives identified in Test Plan TP-WTPSP-031 did not apply to this activity but, instead, apply to the aerosol testing results that are discussed in other reports. Table S.1 summarizes the results of the plugging tests and discusses how the objectives were met. 
Table S.1. Summary of Test Objectives and Results

\begin{tabular}{|c|c|c|}
\hline Test Objective & $\begin{array}{c}\text { Objective } \\
\text { Met? }\end{array}$ & Discussion \\
\hline \multirow[t]{2}{*}{$\begin{array}{l}\text { Determine the size of circular and } \\
\text { slot-shaped breaches that will plug } \\
\text { and not form appreciable sprays with } \\
\text { slurry simulants within an } \\
\text { appropriate time period [such as } \\
15 \text { minutes]. }\end{array}$} & Yes & $\begin{array}{l}\text { Plugging was observed in most but not all of the tests with the } \\
\text { smallest circular hole. The diameter of this orifice was } \\
\text { measured as } 0.245 \mathrm{~mm} \text { on the outside of the test piece, with a } \\
\text { smaller diameter of } 0.188 \mathrm{~mm} \text { on the inside of the test piece. } \\
\text { Orifices smaller than this were not tested because of fabrication } \\
\text { difficulties caused by the large aspect ratio (tube wall } \\
\text { thickness/orifice diameter). Because the smallest orifice tested } \\
\text { did not plug consistently, the orifice dimensions that can be } \\
\text { assumed to consistently plug are smaller than those tested. }\end{array}$ \\
\hline & & $\begin{array}{l}\text { Larger circular holes never plugged. No plugging was observed } \\
\text { during testing of the slots. The smallest slot tested was } \\
0.269 \times 4.946 \mathrm{~mm} \text { (width } \times \text { length) based on measurements } \\
\text { taken on the outside of the test piece. The orifice dimensions on } \\
\text { the inside of the test piece are expected to be smaller than the } \\
\text { dimensions on the outside of the test piece and may be } \\
\text { measured later using destructive methods when the test pieces } \\
\text { are no longer needed for additional tests. }\end{array}$ \\
\hline
\end{tabular}

\section{S.2 Results and Performance Against Success Criteria}

The success criteria for achieving the test objective are discussed in Table S.2. Only the success criteria for the small-scale plugging tests are given in the table. The success criteria for the aerosol tests are not shown in this table and are discussed in Mahoney et al. 2012 and Schonewill et al. 2012.

Table S.2. Success Criteria for Small-Scale Plugging Tests

\begin{tabular}{lcl}
\multicolumn{1}{c}{ Success Criteria } & $\begin{array}{c}\text { Objective } \\
\text { Met? }\end{array}$ & \multicolumn{1}{c}{$\begin{array}{c}\text { How Testing Did or Did Not Meet } \\
\text { Success Criteria }\end{array}$} \\
\hline $\begin{array}{l}\text { Visually observe the formation of sprays to determine if } \\
\text { significant breach plugging occurs within an appropriate } \\
\text { time (typically } 15 \text { min). }\end{array}$ & $\mathrm{Y}$ & $\begin{array}{l}\text { Spraying through the various orifices } \\
\text { was visually observed for } 15 \text { min. }\end{array}$ \\
$\begin{array}{l}\text { Measure the pressure and flow in the piping. } \\
\text { Characterize the slurry simulant particle size }\end{array}$ & $\mathrm{Y}$ & $\begin{array}{l}\text { The pressure and flow in the piping } \\
\text { were measured and recorded in a Test } \\
\text { Instruction (TI) datasheet and with a } \\
\text { data logger. }\end{array}$ \\
distributions and rheology for each slurry tested. & Y & $\begin{array}{l}\text { The three simulants tested were } \\
\text { characterized prior to testing and in } \\
\text { many cases after testing. }\end{array}$ \\
\hline
\end{tabular}

\section{S.3 Quality Requirements}

The PNNL Quality Assurance (QA) Program is based upon the requirements defined in the U.S. Department of Energy Order 414.1D, Quality Assurance, and 10 CFR 830, Energy/Nuclear Safety Management, and Subpart A-Quality Assurance Requirements (a.k.a., the Quality Rule). PNNL has chosen to implement the following consensus standards in a graded approach: 
- ASME NQA-1-2000, Quality Assurance Requirements for Nuclear Facility Applications, Part 1, Requirements for Quality Assurance Programs for Nuclear Facilities

- ASME NQA-1-2000, Part II, Subpart 2.7, Quality Assurance Requirements for Computer Software for Nuclear Facility Applications

- ASME NQA-1-2000, Part IV, Subpart 4.2, Graded Approach Application of Quality Assurance Requirements for Research and Development.

The procedures necessary to implement the requirements are documented through PNNL's "How Do I...?" $\left(\mathrm{HDI}^{1}\right)$ system.

The Waste Treatment Plant Support Project (WTPSP) implements an NQA-1-2000 Quality Assurance Program, graded on the approach presented in NQA-1-2000, Part IV, Subpart 4.2. The WTPSP Quality Assurance Manual (QA-WTPSP-0002) describes the technology life cycle stages under the WTPSP Quality Assurance Plan (QA-WTPSP-0001). The technology life cycle includes the progression of technology development, commercialization, and retirement in process phases of basic and applied research and development (R\&D), engineering and production and operation until process completion. The life cycle is characterized by flexible and informal quality assurance activities in basic research, which becomes more structured and formalized through the applied R\&D stages.

The work described in this report has been completed under the QA technology level of Developmental Work. WTPSP addresses internal verification and validation activities by conducting an Independent Technical Review of the final data report in accordance with WTPSP's procedure QA-WTPSP-601, Document Preparation and Change. This review verifies that the reported results are traceable, that inferences and conclusions are soundly based, and that the reported work satisfies the test plan objectives.

\section{S.4 Simulant Use}

Several simulants have been developed and characterized for use in the small-scale plugging and aerosol tests. The simulants have been selected to represent a range of relevant physical and rheological properties expected in the WTP (Table S.3). The properties important to plugging and aerosol generation include viscosity, Bingham plastic rheological parameters (yield stress and plastic viscosity), density, and surface tension. The particle size, solids loading and rheology are considered the most important properties for investigating orifice plugging.

The simulants used in the plugging tests consisted of mixtures of water and boehmite or gibbsite with a range of particle sizes and solids content ( 8 and $20 \mathrm{wt} \%$ ). The simulant with the smallest particle size distribution (PSD) was identified as "small treated" (STR), and consisted of two different commercially available boehmite powders suspended in water. It was developed to target the PSD of an actual waste sample that had been processed through the WTP pretreatment steps and had a relatively small particle size. The simulant with the next largest particle size was identified as "small as-received" (SAR), and consisted of a mixture of two different commercially available boehmite powders suspended in water. It was developed to target the lower $5^{\text {th }}$ percentile of PSDs based on PSDs from a number of actual waste

\footnotetext{
${ }^{1}$ HDI is a web-based system for managing the delivery of PNNL policies, requirements, and procedures.
} 
samples. The simulant with the largest particle size was identified as "typical as-received" (TAR), and consisted of a commercially available gibbsite powder suspended in water. This simulant was developed to target the mid-range of the PSDs based on a range of PSDs from a number of actual waste samples.

Table S.3. Target Simulants and the WTP Process Stream Categories

\begin{tabular}{|c|c|c|c|}
\hline Simulant Class & Material & Target Property Range & $\begin{array}{c}\text { WTP Process } \\
\text { Stream Categories }\end{array}$ \\
\hline Baseline & Water & $\begin{array}{l}\text { Viscosity } 1 \mathrm{mPa} \cdot \mathrm{s}(1 \mathrm{cP}) \\
\text { density } 1000 \mathrm{~kg} / \mathrm{m}^{3} \\
\text { surface tension } 73 \mathrm{mN} / \mathrm{m}\end{array}$ & \multirow{2}{*}{$\begin{array}{c}\text { Ultrafilter permeate/ } \\
\text { treated low-activity waste } \\
\text { Cs ion exchange eluate } \\
\text { Recycle streams }\end{array}$} \\
\hline $\begin{array}{l}\text { Ranges of } \\
\text { Newtonian } \\
\text { viscosities }\end{array}$ & $\begin{array}{l}\text { Solutions of water and } \\
\text { non-hazardous salts (sodium } \\
\text { nitrate and sodium } \\
\text { thiosulfate) }\end{array}$ & $\begin{array}{l}\text { Viscosities of } \sim 1.5, \sim 2.5 \mathrm{mPa} \cdot \mathrm{s} \\
(1.5,2.5 \mathrm{cP})\end{array}$ & \\
\hline $\begin{array}{l}\text { Range of slurries } \\
\text { (non-hazardous) }\end{array}$ & $\begin{array}{l}\text { Gibbsite and boehmite } \\
\text { particulates in water }\end{array}$ & $\begin{array}{l}\text { The PSDs of the slurries were } \\
\text { selected to match Hanford waste } \\
\text { PSDs (average waste feed and } \\
\text { representatively-small PSDs, } \\
\text { because smaller PSDs are least } \\
\text { likely to plug breaches). } \\
8 \text { and } 20 \mathrm{wt} \% \text { solids }\end{array}$ & $\begin{array}{c}\text { Newtonian slurries } \\
\text { Non-Newtonian slurries }\end{array}$ \\
\hline $\begin{array}{l}\text { Washed and } \\
\text { leached chemical } \\
\text { slurry simulant }\end{array}$ & $\begin{array}{l}\text { A washed and leached } \\
\text { version of the simulant used } \\
\text { in Pretreatment Engineering } \\
\text { Platform (PEP) testing } \\
\text { (Kurath et al. 2009) }\end{array}$ & $\begin{array}{l}\text { Solids loading was adjusted to } \\
\text { meet target Bingham yield } \\
\text { stresses of } 6 \text { and } 30 \mathrm{~Pa}\end{array}$ & Non-Newtonian slurries \\
\hline
\end{tabular}

A summary of the measured physical and rheological properties is shown in Table S.4. The simulant identifier in the first column is discussed in the previous paragraph with the -8 and -20 indicating the target solids loading with units of wt $\%$ undissolved solids (UDS). The properties listed in the table were measured with samples taken directly from the feed tank prior to testing. The rheology of the STR-8 sample was unexpectedly high so separate samples of STR-8 and STR-20 were prepared and additional measurements obtained. These results, denoted as "later batch," are consistent with the expected values. Additional discussion of the simulants may be found in Chapter 3 .

\section{S.5 Summary of Results}

The study provided experimental data for plugging of small breaches by testing a range of orifice sizes and orientations representative of the WTP conditions. In general, these slurry simulants were Newtonian or weakly non-Newtonian; the highest Bingham yield stress measured was 1.5 Pa.

The main results of the plugging tests are shown in Table S.5. The simulant identifiers in the first column are discussed in the previous simulant section with the -8 and -20 indicating the target solids loading with units of wt\% UDS. Except for one case the tests were conducted with the fluid flowing past the orifice as indicated by "axial" in the third column. In one test, the line was blocked and the test 
conducted in a dead-end configuration. Each test was conducted for $15 \mathrm{~min}$, and the plugging time was noted by visual observation of the spray for the orifices that plugged.

Table S.4. Summary of Measured Simulant Properties

\begin{tabular}{|c|c|c|c|c|c|c|}
\hline \multirow[b]{2}{*}{ Simulant } & \multicolumn{4}{|c|}{ Particle Sizes $(\mu \mathrm{m})$ by Volume Percentile } & \multicolumn{2}{|c|}{ Rheological Properties } \\
\hline & $10^{\text {th }}$ & $50^{\text {th }}$ & $90^{\text {th }}$ & $100^{\text {th }}$ & $\begin{array}{l}\text { Bingham yield } \\
\text { stress }(\mathrm{Pa})\end{array}$ & $\begin{array}{l}\text { Bingham } \\
\text { consistency } \\
(\mathrm{mPa} \cdot \mathrm{s})\end{array}$ \\
\hline SAR-8 & 1.2 & 3.0 & 14 & 40 & 0.1 & 1.6 \\
\hline SAR-20 & 1.2 & 2.8 & 13 & 40 & 0.9 & 3.0 \\
\hline TAR-8 & 1.7 & 8.4 & 25 & 56 & 0 & 1.2 \\
\hline TAR-20 & 1.8 & 8.8 & 26 & 56 & 0.1 & 1.6 \\
\hline STR-8 (batch used in test feed) & 0.48 & 0.98 & 2.2 & 20 & 1.4 & 3.0 \\
\hline STR-8 (later batch) & $\mathrm{n} / \mathrm{m}$ & $\mathrm{n} / \mathrm{m}$ & $\mathrm{n} / \mathrm{m}$ & $\mathrm{n} / \mathrm{m}$ & 0 & 1.3 \\
\hline STR-20 (batch used in test feed) & 0.45 & 0.91 & 2.0 & 16 & 0 & 1.5 \\
\hline STR-20 (later batch) & $\mathrm{n} / \mathrm{m}$ & $\mathrm{n} / \mathrm{m}$ & $\mathrm{n} / \mathrm{m}$ & $\mathrm{n} / \mathrm{m}$ & 0 & 1.5 \\
\hline
\end{tabular}

Table S.5. Results of Plugging Tests

\begin{tabular}{|c|c|c|c|c|c|c|c|c|}
\hline \multirow[b]{2}{*}{ Simulant } & \multirow{2}{*}{$\begin{array}{c}\text { Target } \\
\text { Pressure } \\
\text { (psig) }\end{array}$} & \multirow[b]{2}{*}{$\begin{array}{c}\text { Flow } \\
\text { Orientation }\end{array}$} & \multicolumn{4}{|c|}{ Circular (time to plug, min:sec) } & \multicolumn{2}{|c|}{ Slot (b) } \\
\hline & & & $\begin{array}{c}0.245 \mathrm{~mm}^{\text {(a) }} \\
0.188 \mathrm{~mm}^{2}\end{array}$ & $\begin{array}{c}0.382 \\
\mathrm{~mm}\end{array}$ & $\begin{array}{c}0.534 \\
\mathrm{~mm}\end{array}$ & $\begin{array}{c}0.706 \\
\mathrm{~mm}\end{array}$ & $\begin{array}{c}0.260 \times 4.946 \\
\mathrm{~mm}\end{array}$ & $\begin{array}{c}0.357 \mathrm{x} \\
5.021 \mathrm{~mm} \\
\end{array}$ \\
\hline STR-8 & 100 & axial & - & - & - & - & - & NT \\
\hline STR-8 & 200 & axial & $\mathrm{P}(1: 55)$ & - & - & - & - & NT \\
\hline STR-8 & 380 & axial & $\mathrm{P}(5: 32)$ & - & - & - & - & NT \\
\hline STR-8 & 380 & dead-end & $\mathrm{P}(0: 15)$ & - & NT & NT & NT & NT \\
\hline STR-20 & 380 & axial & $\mathrm{P}(9: 20)$ & - & - & - & - & - \\
\hline SAR-8 & 100 & axial & $P(6: 15)$ & - & - & - & NT & NT \\
\hline SAR-8 & 380 & axial & $\mathrm{P}(2: 39)$ & - & - & - & NT & NT \\
\hline SAR-20 & 200 & axial & $\mathrm{P}(13: 55)$ & - & - & - & NT & NT \\
\hline SAR-20 & 380 & axial & $\mathrm{P}(1: 32)$ & - & - & - & NT & NT \\
\hline TAR-8 & 380 & axial & - & - & - & - & - & - \\
\hline TAR-20 & 380 & axial & $\mathrm{P}(1: 29)$ & - & - & - & - & - \\
\hline
\end{tabular}

(a) Orifice dimension on inside of the Orifice Test Piece (OTP). Other dimensions are on the outside of the OTP. "P" = spray stopped by plugging with simulant.

"_" = test showed no plugging.

"NT" = not tested.

(b) The OTP slot orifices were oriented longitudinally, with the slot length along the flow direction.

No combination of simulant and pressure produced plugging for round orifices with an outer diameter $\geq 382 \mu \mathrm{m}$ or for slots with a smallest outer dimension (width) $\geq 260 \mu \mathrm{m}$. The smallest round orifice tested had a diameter of $0.188 \mathrm{~mm}$ at the inside of the OTP; it plugged in 9 of the 11 tests. All of the tests at $20 \mathrm{wt} \%$ UDS plugged the smallest orifice. 
One of the tests in which the smallest orifice did not plug used a simulant that represented the smallest PSD (STR) with a solids concentration of $8 \mathrm{wt} \%$ UDS ( $2.8 \mathrm{vol} \%$ solid $)$. For this simulant, the maximum measured particle size, $20 \mu \mathrm{m}$, was larger than the maximum target particle size, $8 \mu \mathrm{m}$. The target PSDs were based on measurements obtained on an actual waste sample that had been washed and leached. The target STR simulant might be less likely to cause plugging than the actual STR simulant, based on particle size alone. However, since cohesion played a part in plugging with STR, it is not clear that decreased particle size would offset the cohesiveness and reduce the chances of plugging.

The other test that did not plug the smallest orifice used a simulant that represented a TAR waste with a solids concentration of $8 \mathrm{wt} \%$ (3.5 vol\% solid). The maximum measured particle size, $56 \mu \mathrm{m}$, was smaller than the maximum target particle size, $792 \mu \mathrm{m}$. In this case the target simulant would contain particles whose orifice/particle ratio would be $<1$ for the smallest orifice tested, as well as for several larger OTPs. Plugging would be nearly unavoidable for ratios $<1$.

The test results indicate that orifice plugging may be a function of solids concentration, but there is no observable plugging trend as a function of simulant particle size over the size range tested. Given that some of the actual wastes have particles larger than the maximum particle size of the simulants, it is likely that some, but not all, actual wastes could consistently plug the orifices tested.

In general, no consistent distinction could be made between the simulants in terms of plugging behavior, nor was there any recognizable trend with particle size or cohesiveness. There also was no clear trend to demonstrate an effect of pressure (flow velocity) on plugging. The orifice dimensions that can be assumed to consistently plug are smaller than the orifice dimensions tested with the range of simulants and pressures indicated in Table S.5.

\section{S.6 Discrepancies and Follow-on Tests}

The discrepancies related to the planned tests are discussed below.

Some of the measured orifice sizes, as measured on the outside of the test pieces, were larger than specified. This is thought to be due to the fabrication technique that generally resulted in slightly larger orifice sizes on the outside of the pipe. Attempts to determine the dimensions of the orifice where it intersects the inner diameter of the pipe, while viewing from the outer diameter, were unsuccessful. This was largely due to the small orifices acting as pinhole lenses, producing a falsely magnified image of the inner diameter orifice size. This only impacted orifice dimensions smaller than $1 \mathrm{~mm}$. Alternative methods to obtain inner dimensions produced unreliable results, and destructive methods of examination were generally not pursued because the OTPs were needed throughout testing. The exception was the smallest orifice with a target diameter of $0.2 \mathrm{~mm}$. In this case, a hole was drilled through the back of the OTP so the inner orifice diameter could be measured.

The originally planned plugging tests involving the non-Newtonian washed and leached chemical slurry simulants were to have been performed together with the small-scale spray aerosol tests. Plugging tests with this simulant were not completed because the aerosol results indicated that the smaller orifices did not result in an overall increase in aerosol generation. Because the bounding releases for the WTP hazards analysis involves larger orifices, there was little value in completing these tests. 


\section{Acknowledgments}

The authors would like to thank Bill Buchmiller, Jesse Lang, Craig Lukins, Rebecca Erikson, and Laura Turo for their painstaking and indefatigable performance of the plugging tests. Many thanks are also owed to Phil Schonewill and Garrett Brown for their analysis of the orifice image data and review of this report. We also thank Kirsten Meier for her Quality Assurance support.

Funding for this effort was provided by the Department of Energy's Waste Treatment and Immobilization Plant Project. 



\section{Acronyms and Abbreviations}

AFA

ASME

DOE

FER

HDI

LAR

LAW

LRB

ORP

OTP

PEP

PNNL

PSD

QA

R\&T

SAR

STR

TAR

UDS

WTP

WTPSP anti-foam agent

American Society of Mechanical Engineers

U.S. Department of Energy

Fe-rich (iron-rich)

"How Do I," the standards-based management system for PNNL

large as-received

high-volume low-activity waste

Laboratory Record Book

DOE Office of River Protection

orifice test piece

Pretreatment Engineering Platform

Pacific Northwest National Laboratory

particle size distribution

Quality Assurance

Research and Technology

small as-received (this is a simulant identifier)

small treated (this is a simulant identifier)

typical as-received (this is a simulant identifier)

undissolved solid

Hanford Tank Waste Treatment and Immobilization Plant

Waste Treatment Plant Support Project 



\section{Contents}

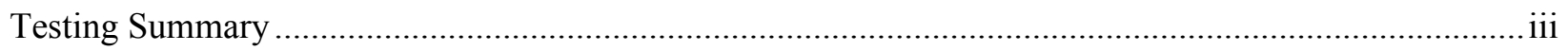

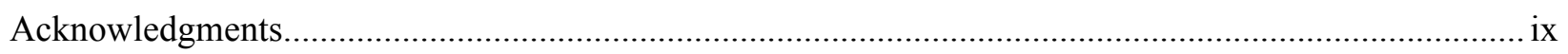

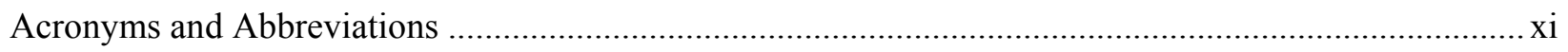

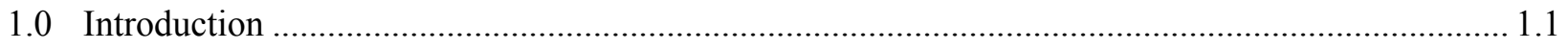

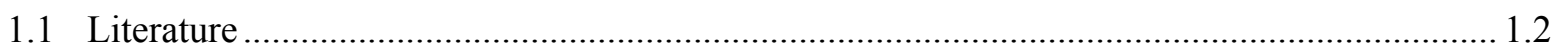

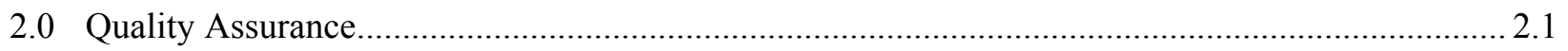

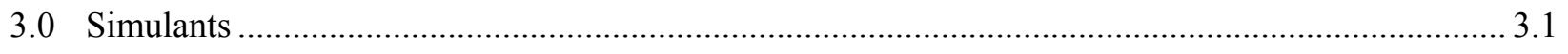

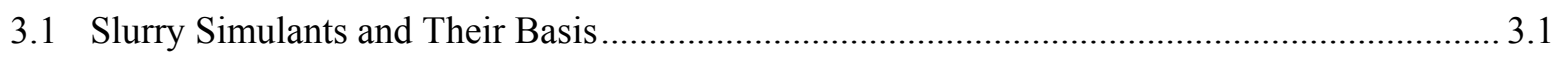

3.1.1 Typical As-Received (TAR) Hanford Waste Simulant............................................... 3.3

3.1.2 Small As-Received (SAR) Hanford Waste Simulant .................................................. 3.7

3.1.3 Small Treated (STR) Hanford Waste Simulant......................................................... 3.8

3.1.4 Additional Simulants Considered for Plugging Tests ............................................... 3.9

3.1.5 Summary of Measured Simulant Properties ............................................................... 3.10

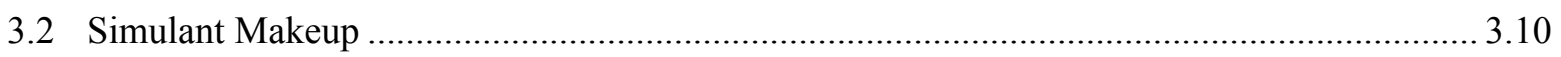

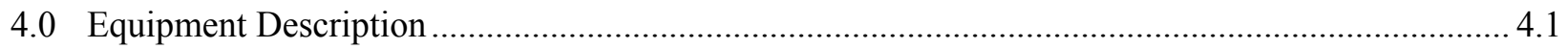

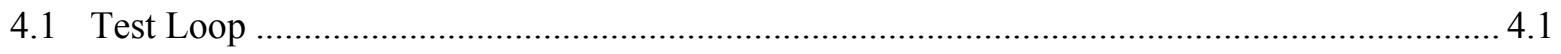

4.2 Test System Data Collection and Instruments .................................................................. 4.3

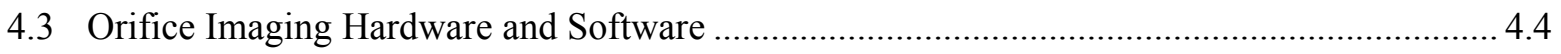

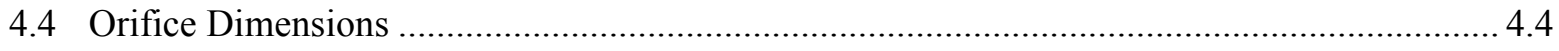

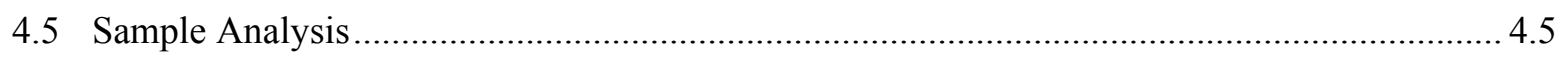

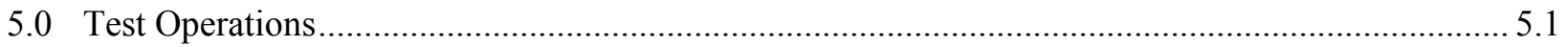

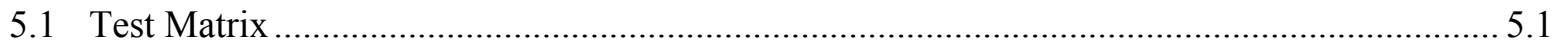

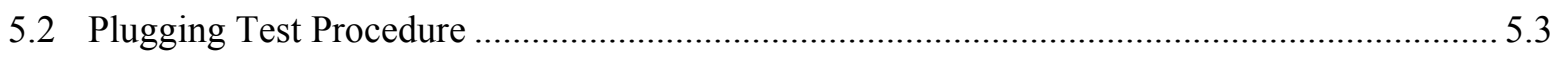

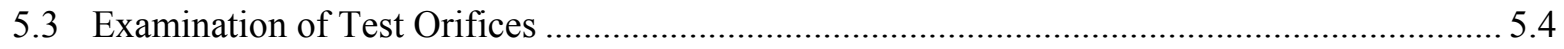

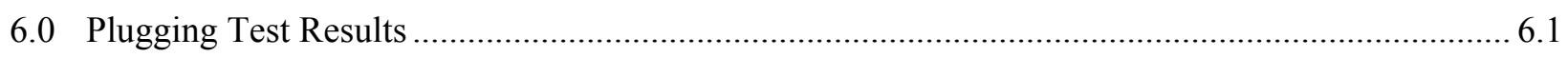

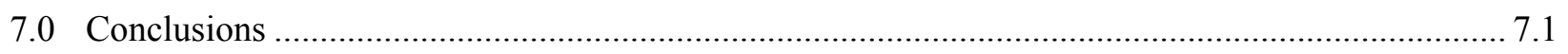

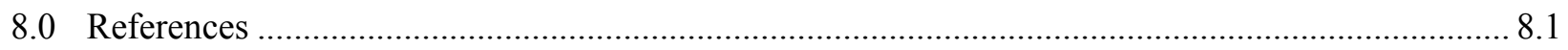

Appendix A - List of Test Documents ........................................................................................ A.1

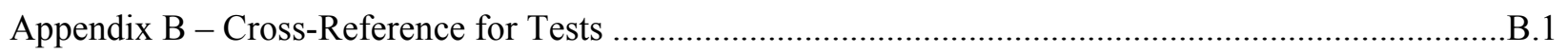




\section{Figures}

3.1. Cumulative PSDs (Flowing-Sonicated) for Sludge Tanks and Waste Groups and for 5th Percentile, Sludge Composite, and 95th Percentile PSDs by UDS Volume. 3.4

3.2. Flowing Sonicated PSDs for Post-Caustic Leached and Washed Waste......................................... 3.5

3.3. TAR Simulant PSD at Two Concentrations and Target Sludge Composite Combined PSD ............ 3.6

3.4. SAR Simulant PSD at Two Concentrations and Target $5^{\text {th }}$ Percentile PSD ................................... 3.8

3.5. STR Simulant PSD at Two Concentrations and PSD of Target Group 1/2 Mixture ........................ 3.9

4.1. Schematic of Small Scale Testing System .................................................................................... 4.2

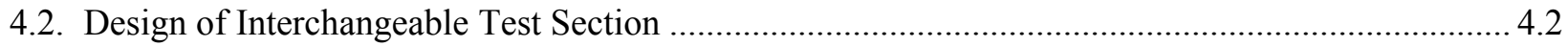

4.3. Enclosure for Small-Scale Testing............................................................................................. 4.3

4.4. Orifice Images Measured Where Orifice Intersects With Outer Diameter of Pipe ......................... 4.4

\section{Tables}

3.1. WTP Process Stream Categories and Representative Fluid Properties ........................................ 3.1

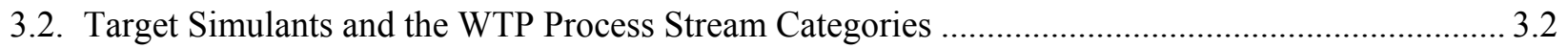

3.3. TAR Simulant PSD Compared to Target Sludge Composite Combined PSD ................................. 3.6

3.4. SAR Simulant PSD Compared to Target 5th Percentile PSD Weighted by UDS Volume ............... 3.7

3.5. STR Simulant PSD Compared to Target Group 1/2 Mixture Flowing Sonicated Combined

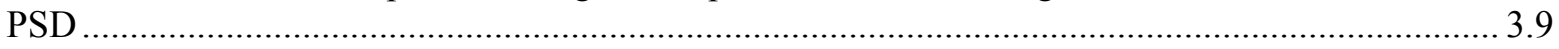

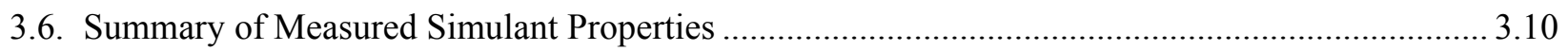

3.7. Masses of Components for Simulant Batches for Plugging Tests ................................................ 3.11

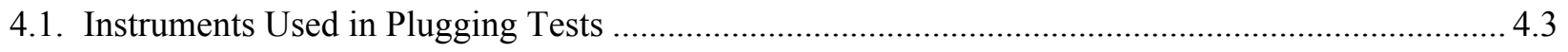

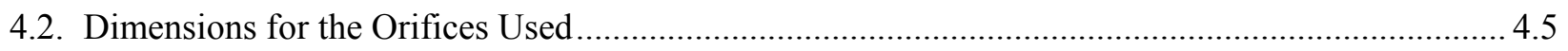

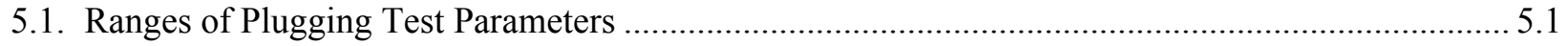

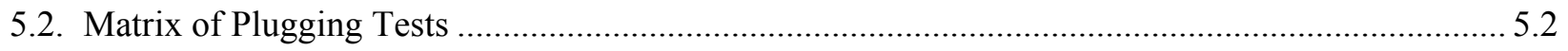

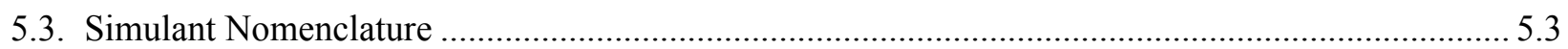

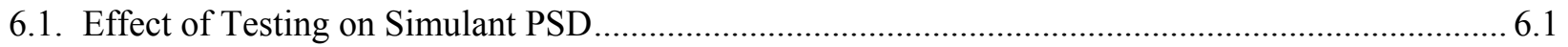

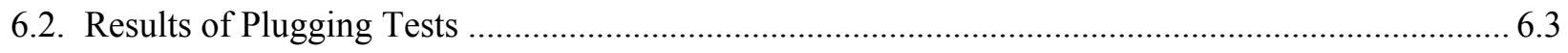

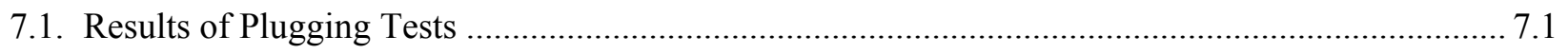




\subsection{Introduction}

One of the events postulated in the hazard analysis for Waste Treatment and Immobilization Plant (WTP) is a breach in process piping that produces a spray with aerosols with droplet sizes in the respirable range. The postulated breach is expected to be rough and irregular, and could result from a number of causes (e.g., jumper connection misalignment, pipe erosion/corrosion, mechanical impact, seal/gasket failures).

In Hanford practice, the generation rate and size distribution of aerosol droplets produced in a spray leak have generally been predicted by extrapolating from correlations in the literature. These correlations are based on results obtained from small engineered spray nozzles using solids-free liquids. However, the fluids processed at WTP include slurries and high viscosity liquids with properties very different than the properties of the liquids used to develop the correlations currently used to evaluate spray leaks. The range of geometries postulated for random breaches differs from the geometry of the engineered spray nozzles used to develop the correlation in terms of both aspect ratio and area. Therefore, the correlations used to model spray leaks from process piping may not accurately represent spray leak conditions at the WTP (or elsewhere on the Hanford site).

The amount of aerosol produced is a function of the dimensions of the opening, which affect both the total amount of flow and the fraction that becomes respirable aerosol. In some of the predictive correlations for aerosol generation, the respirable fraction is insensitive to breach dimensions (Epstein and Plys 2006). In others, the respirable fraction increases significantly as the dimensions of the opening decrease (Hey and Leach 1994). The maximum breach size postulated for WTP spray modeling depends on the pipe size, and for pipe diameter up to 3 in. the maximum opening has a length equal to the pipe diameter and width equal to one-half of the pipe wall thickness (Larson and Allen 2010). Most models in use on the Hanford site set a minimum breach dimension based either on the gas Weber number $\left(\mathrm{We}_{\mathrm{g}}\right)^{1}$ or on plugging considerations. However, arguments have been made, for example, that openings with $\mathrm{We}_{\mathrm{g}}$ $<60$ do not support significant jet breakup and, therefore, do not result in significant aerosol production (Zimmerman 2003), or that openings with a minimum dimension of $<0.7 \mathrm{~mm}$ would be plugged by slurries which contain relatively large particles, such as K-Basin slurries (HNF-SD-WM-SAR-062). In practice, the plugging assumption may determine a minimum breach size, which can limit the estimated amount of aerosol produced if the correlation used to model aerosol predicts greatly increased respirable droplet production as the breach size decreases.

These considerations indicated that there were two key technical areas in which testing results are needed to improve the WTP methodology (Larson and Allen 2010) and reduce uncertainty due to extrapolating existing literature results. The first technical need is to quantify the role of slurry particles in small breaches where the slurry particles may plug the hole and prevent high-pressure sprays. The second technical need is to determine the aerosol droplet size distribution and total droplet volume from prototypic breaches and fluids, including sprays from larger breaches and sprays of slurries where literature data are largely absent. These needs are to be addressed by small-scale testing that employs small quantities of simulants, including some that contain hazardous-waste components, and large-scale testing that consume larger volumes of simulant and are closer to plant scale.

\footnotetext{
${ }^{1}$ The gas Weber number is $\rho_{g} u_{0}^{2} d_{0} / \sigma$, where $\rho_{g}$ is the gas density, $u_{0}$ the liquid velocity at the orifice, $d_{0}$ the diameter of the orifice, and $\sigma$ the surface tenstion.
} 
The purpose of the study described in this report is to provide experimental data for the first key technical area, potential plugging of small breaches, by performing small-scale tests with a range of orifice sizes and orientations representative of the WTP conditions. The simulants used were chosen to represent the range of process stream properties in the WTP. Testing conducted after the plugging tests in the small- and large-scale test stands addresses the second key technical area, aerosol generation. The results of the small-scale aerosol generation tests are included in Mahoney et al. (2012). The area of spray generation from large breaches is covered by large-scale testing in Schonewill et al. (2012).

Chapter 1 of this report provides an introduction and a discussion of related tests found in the literature. Chapter 2 details the basis of the PNNL Quality Assurance (QA) Program as applied to the WTPSP quality requirements. Chapter 3 describes the liquid and slurry simulants used in testing, and the basis for their choice. Chapter 4 provides a description of the equipment and instruments. Chapter 5 summarizes the test operations, Chapter 6 provides the results, and Chapter 7 contains the conclusions of the study. The references are listed in Chapter 8. The appendices provide a list of the technical documents governing the work (Appendix A) and a cross-reference table for the tests (Appendix B).

\subsection{Literature}

A search of the literature found only one article on the subject of slurry solids causing orifice plugging (also called blocking or jamming), although there were a number of articles on jamming by dry granular flows (generally in silo or hopper discharges). Since the materials and conditions studied in the literature are very different from those found in WTP processes, only a brief conceptual summary of a few articles is appropriate here.

In dry granular flows through orifices, the mechanism that causes jamming is that of "arching." There is a critical orifice diameter above which jamming does not occur or is extremely improbable. In the case of monodisperse spheres flowing through an outlet in the flat-bottomed silo, the critical orifice diameter was found to be about 5 particle diameters (Zuriguel et al 2005). The critical diameter would have been affected by the slope of the silo bottom (which was not tested) and was affected by particle shape. It was not affected by size variation of up to $12 \%$, or particle material properties (for a range including metal, glass, and soft materials such as lentils and rice).

Hirochi et al. (2002) studied ice-water slurries flowing through $15-\mathrm{mm}$ or $25-\mathrm{mm}$ orifices at one end of an acrylic pipe of 52-mm inner diameter. Orifice velocities of $0.2-27 \mathrm{~m} / \mathrm{s}$ were generated by a piston at the other end of the pipe, and the materials in the slurries were polypropylene beads, ice chips, granulated snow, and fresh snow at concentrations of up to $32 \%$. In general, blocking depended on orifice diameter, velocity, and concentration. For small orifice diameters (less than roughly 3 particle diameters) arching appeared to cause the blockage. In these cases, blockages could occur for the less cohesive materials (the beads and the chip ice) as well as the more cohesive. At larger orifice diameters, only the more cohesive materials (snows) produced blockages, and the mechanism appeared to be small clusters stagnating at the orifice and growing into volume-filling plugs that had some compressive strength. For this type of plug, increasing the velocity increased the minimum concentration that was required for blockage. In other words, increasing the velocity decreased the chance of blockage, and increasing the concentration increased the chance of blockage. However, above a certain critical concentration, increases in the velocity did not reduce the chance of blockage. 
The clogging of packed beds by particles in suspensions, which has received more study, may also be relevant to breach plugging. It is similar in that it involves the flow of particles through openings less than a millimeter in size. These pores are irregular passages and crevices, rather than through the simple circular or rectangular openings used in the studies already cited. Packed-bed clogging differs from breach plugging in that the velocities in packed beds are low, of the order of $1 \mathrm{~mm} / \mathrm{s}$ for deep-bed filters, compared to velocities of $20-50 \mathrm{~m} / \mathrm{s}$ in breach releases.

Herzig et al (1970) describe the clogging mechanisms present in deep filtration with packed beds. The wedging of particles in crevices is likely to be a significant contributor to clogging at higher particle velocities where the kinetic energy is high enough to force the wedging. Using geometric arguments, Herzig et al. (1970) estimate the minimum diameter of a single particle that can wedge into and clog the pore throat between closely packed monodisperse bed grains as equal to the maximum width of the pore throat, $15.4 \%$ of the grain diameter. If three particles wedge simultaneously, the minimum diameter of the particles in the clog is $10 \%$ of the grain diameter. If there are four particles, the minimum diameter of the particles in the clog is $8.2 \%$ of the grain diameter. Thus, the theoretical ratio of the pore diameter to the minimum particle diameter for clogging is 1 for a single particle, 1.5 for three particles, and 1.9 for four particles. Studies cited by Herzig et al. (1970) indicated that partial clogging can occur when the particles in the suspension are as small as $6.5 \%$ of the grain diameter, implying a ratio of pore to particle diameter of 2.4 .

Higher concentrations of particles in a suspension increases the likelihood that multiple particles can simultaneously wedge in an orifice and reduces the size of the particles that may be required to form a plug. Pandya et al (1998) tested and confirmed this concentration effect using suspensions of polystyrene beads flowing through beds of glass beads. The same study also found that, for a given concentration of particles, plugging was likelier to occur at higher interstitial velocities than at lower. The opposite effect of velocity had been found in the ice slurry tests of Hirochi et al. (2002), possibly because the higher velocities in those tests produced a different regime of plugging behavior.

Generally speaking, the literature provides ambiguous guidance about the effect of flow velocity on plugging of orifices by slurries. There is also no quantitative rule of thumb for the effect of particle size and concentration in polydisperse suspensions. 



\subsection{Quality Assurance}

The PNNL QA Program is based upon the requirements defined in the U.S. Department of Energy Order 414.1D, Quality Assurance, and 10 CFR 830, Energy/Nuclear Safety Management, and Subpart A-Quality Assurance Requirements (a.k.a. the Quality Rule). PNNL has chosen to implement the following consensus standards in a graded approach:

- ASME NQA-1-2000, Quality Assurance Requirements for Nuclear Facility Applications, Part 1, Requirements for Quality Assurance Programs for Nuclear Facilities.

- ASME NQA-1-2000, Part II, Subpart 2.7, Quality Assurance Requirements for Computer Software for Nuclear Facility Applications.

- ASME NQA-1-2000, Part IV, Subpart 4.2, Graded Approach Application of Quality Assurance Requirements for Research and Development.

The procedures necessary to implement the requirements are documented through PNNL's "How Do I...?" (HDI $\left.{ }^{1}\right)$.

The Waste Treatment Plant Support Project (WTPSP) implements an NQA-1-2000 Quality Assurance Program, graded on the approach presented in NQA-1-2000, Part IV, Subpart 4.2. The WTPSP Quality Assurance Manual (QA-WTPSP-0002) describes the technology life cycle stages under the WTPSP Quality Assurance Plan (QA-WTPSP-0001). The technology life cycle includes the progression of technology development, commercialization, and retirement in process phases of basic and applied research and development $(R \& D)$, engineering and production, and operation until process completion. The life cycle is characterized by flexible and informal quality assurance activities in basic research, which becomes more structured and formalized through the applied R\&D stages.

The work described in this report has been completed under the QA technology level of Developmental Work. WTPSP addresses internal verification and validation activities by conducting an Independent Technical Review of the final data report in accordance with WTPSP's procedure QA-WTPSP-601, Document Preparation and Change. This review verifies that the reported results are traceable, that inferences and conclusions are soundly based, and that the reported work satisfies the test plan objectives.

\footnotetext{
${ }^{1}$ System for managing the delivery of PNNL policies, requirements, and procedures.
} 



\subsection{Simulants}

This section lists the slurry simulants used in the plugging tests, states the basis for their selection, and describes the methods used to make the simulants. The slurry simulants are discussed in Section 3.1. The preparation methods are described in Section 3.2.

\subsection{Slurry Simulants and Their Basis}

Table 3.1 summarizes the WTP process streams and typical ranges for important fluid properties. ${ }^{1}$ The ranges of properties and descriptions are generalized representations; actual waste examples may vary. The process stream categories shown in Table 3.1 are those that were chosen to be simulated in the spray leak testing.

Table 3.1. WTP Process Stream Categories and Representative Fluid Properties

\begin{tabular}{llll}
\hline \multicolumn{1}{c}{$\begin{array}{c}\text { WTP Process } \\
\text { Stream Categories }\end{array}$} & \multicolumn{1}{c}{ Solids } & \multicolumn{1}{c}{ Composition } & \multicolumn{1}{c}{ Viscosity Rheology } \\
\hline Ultrafilter Permeate & negligible & Caustic solution & Newtonian \\
Treated LAW & & $5-10 \mathrm{M} \mathrm{Na}$ & $2-3 \mathrm{cP}$ \\
Cs Ion Exchange Eluate & negligible & $\mathrm{Na}, \mathrm{K}, \mathrm{Cs}$ ions with $0.5 \mathrm{M}$ & Newtonian \\
& & $\mathrm{Nitric} \mathrm{Acid}$ & $0.5 \mathrm{cP}$ and above \\
Recycle Streams & $<2 \mathrm{wt} \%$ & $0.2-2 \mathrm{M} \mathrm{Na}$ & Newtonian \\
& & & $0.5 \mathrm{cP}$ and above \\
Newtonian Slurries & about $2-16{\mathrm{wt} \%{ }^{(\mathrm{a})}}$ & up to $8 \mathrm{M} \mathrm{Na}$ & Newtonian ${ }^{(\mathrm{b})}$ \\
& & & about $1-3 \mathrm{cP}$ \\
& & $0.2-2 \mathrm{M} \mathrm{Na}$ & Non-Newtonian \\
Non-Newtonian Slurries & up to $\sim 20 \mathrm{wt} \%$ & & $6 \mathrm{cP} / 6 \mathrm{~Pa}$ to \\
& & & $30 \mathrm{cP} / 30 \mathrm{~Pa}$ \\
\hline
\end{tabular}

(a) The upper limit of about $16 \mathrm{wt} \%$ corresponds to a limit of $200 \mathrm{~g} / \mathrm{L}$ in the waste acceptance criteria (ICD19 2011). A new upper limit of $144 \mathrm{~g} / \mathrm{L}$ in $7 \mathrm{M} \mathrm{Na}$ feed has been recommended and this corresponds to about $10 \mathrm{wt} \%$ solids (Campbell et al. 2010).

(b) This category could also be a weakly non-Newtonian fluid based on the feed acceptance criteria allowing up to 1 Pa Bingham yield stress slurries to be delivered to the WTP (ICD-19 2011). ${ }^{2}$

Table 3.2 summarizes the four target simulant classes presented in the test plan for the spray leak testing effort. ${ }^{3}$ The four simulant classes and materials were chosen to represent the range of wastes shown in Table 3.1. The last column in Table 3.2 shows how each simulant represents one or more of the WTP process stream categories. Water was used for shakedown testing. Two aqueous salt solutions with different viscosities, obtained by adjusting the salt concentration, were chosen to represent process streams in the WTP that are Newtonian fluids but with higher viscosities than water. The primary process streams in the WTP that are represented by these Newtonian liquid simulants include the ultrafilter

\footnotetext{
${ }^{1}$ These categories and ranges of process parameters were provided as guidance for proposal preparation.

${ }^{2}$ ICD 19. 2011. ICD 19 - Interface Control Document for Waste Feed, 24590 WTP ICD MG 01 19, Rev 5, River Protection Project, Richland, Washington.

${ }^{3}$ Gauglitz PA. 2011. Test Plan for Spray Leak Quantification to Support WTP Spray Release Methodology, TP-WTPSP-031 R0.1.
} 
permeate, treated LAW, Cs ion exchange eluate, and recycle streams. There are a number of process streams in the WTP that consist of slurries with a range of solids concentrations. The rheology of the slurries ranges from being essentially Newtonian fluids to non-Newtonian materials. The slurries in the WTP were represented by non-hazardous particles with different PSDs in water or dilute salt solutions and by a washed and leached version of the simulant used in the Pretreatment Engineering Platform (PEP) testing. Because the liquid simulants were solids-free, they were used only for the aerosol tests and not the plugging tests (Mahoney et al. 2012).

Table 3.2. Target Simulants and the WTP Process Stream Categories

\begin{tabular}{|c|c|c|c|}
\hline Simulant Class & Material & Target Property Range & $\begin{array}{c}\text { WTP Process } \\
\text { Stream Categories }\end{array}$ \\
\hline Baseline & Water & $\begin{array}{l}\text { Viscosity } 1 \mathrm{mPa} \cdot \mathrm{s}(1 \mathrm{cP}) \\
\text { density } 1000 \mathrm{~kg} / \mathrm{m}^{3} \\
\text { surface tension } 73 \mathrm{mN} / \mathrm{m}\end{array}$ & $\begin{array}{l}\text { Ultrafilter Permeate/ } \\
\text { Treated LAW }\end{array}$ \\
\hline $\begin{array}{l}\text { Range of } \\
\text { Newtonian } \\
\text { Viscosity }\end{array}$ & $\begin{array}{l}\text { Solutions of water and } \\
\text { non-hazardous salts (sodium } \\
\text { nitrate and sodium acetate) }\end{array}$ & $\begin{array}{l}\text { Viscosities of } \sim 1.5, \sim 2.5 \mathrm{mPa} \cdot \mathrm{s} \\
(1.5,2.5 \mathrm{cP})\end{array}$ & $\begin{array}{c}\text { Cs Ion Exchange Eluate } \\
\text { Recycle Streams }\end{array}$ \\
\hline $\begin{array}{l}\text { Range of Slurries } \\
\text { (non-hazardous) }\end{array}$ & $\begin{array}{l}\text { Gibbsite, boehmite or other } \\
\text { non-hazardous particulates } \\
\text { in water or dilute salt } \\
\text { solutions }\end{array}$ & $\begin{array}{l}\text { Particle size distributions (PSDs) } \\
\text { of slurries were selected to match } \\
\text { Hanford waste PSDs (average } \\
\text { waste feed and } \\
\text { representatively-small PSDs, } \\
\text { because smaller PSDs are least } \\
\text { likely to plug breaches). } \\
8 \text { and } 20 \mathrm{wt} \% \text { solids }\end{array}$ & $\begin{array}{c}\text { Newtonian Slurries } \\
\text { Non-Newtonian Slurries }\end{array}$ \\
\hline $\begin{array}{l}\text { Washed and } \\
\text { Leached Chemical } \\
\text { Slurry Simulant }\end{array}$ & $\begin{array}{l}\text { A washed and leached } \\
\text { version of the simulant used } \\
\text { in PEP testing (Kurath et al. } \\
\text { 2009) }\end{array}$ & $\begin{array}{l}\text { Solids loading was adjusted to } \\
\text { meet target Bingham yield } \\
\text { stresses of } 6 \text { and } 30 \mathrm{~Pa}\end{array}$ & Non-Newtonian Slurries \\
\hline
\end{tabular}

The PSDs for the simulants used in plugging tests were selected based on the available PSD data for Hanford waste. Simulants representing the washed and leached process stream were included because this stream is expected to present a relatively high spray release hazard.

Wells et al. (2011) provides composite combined PSDs for both unprocessed sludge and unprocessed saltcake waste. Given the expected dilutions required for the waste retrieval and feed operations, only sludge waste (i.e., waste in which greater than $75 \mathrm{vol} \%$ of the solid phase is insoluble) was considered appropriate for the waste as-received by the WTP. These PSDs are termed "composite" because they are the undissolved solid (UDS) volume-weighted composite of available tank waste PSDs and "combined" because the volume-weighted PSDs are formed from multiple measurements on a given tank by 1) determining the probability associated with each particle size, 2) ordering the particle sizes by increasing size, and 3) determining the cumulative probability of each size. 
Different PSDs may be determined based on the flow rate and presence/absence of sonication in the PSD instrument during measurement. Because waste feed and retrieval operations may potentially break up flocs or soft agglomerates, the set of PSDs referred to as "Sludge, Flowing Sonicated" (Wells et al. 2011) were used because they best represented the size distribution expected in the shear conditions in turbulent pipe flow and spray leaks. In addition, it is known that the PSDs measured with the sample flowing and with sonication used in the instrument often give the smallest PSDs for a given sample. Because a slurry with the smallest particle size is least likely to plug a breach, using the flowing-sonicated PSDs should provide conservative simulant for testing.

Figure 3.1 shows the specific PSDs from Wells et al. (2011) considered most appropriate for spray leak behavior of as-received waste as described above. As shown, significant variation exists between the PSDs of wastes from different tanks. Within the PSD for any given tank waste, the diameters typically vary by about a factor of 100 . Because breach plugging was expected to depend on the PSD of the slurry particles, three representative PSDs were selected based on these data. Figure 3.1 shows these three PSDs as the $5^{\text {th }}$ percentile curve, sludge composite curve, and the $95^{\text {th }}$ percentile curve.

The sludge composite, Flowing Sonicated PSD was developed by Wells et al. (2011) based on data from actual waste testing. If a tank waste is considered to be "represented" with respect to particle size regardless of the number of measurements for a given tank, then PSDs for approximately 6 percent of the Hanford waste UDS volume and 30 percent of the Hanford waste sludge UDS volume are represented by the Sludge Composite, Flowing Sonicated PSD. The $5^{\text {th }}$ and $95^{\text {th }}$ percentile PSDs were obtained by using a volume-weighted combination of the individual PSDs in Figure 3.1 and determining the appropriate particle sizes representing the $5^{\text {th }}$ and $95^{\text {th }}$ percentiles for the full distribution.

Figure 3.2 shows the sonicated PSDs for post-caustic leached and washed actual waste samples from Wells et al. (2011). Because the treatment of the samples removed the solids that were susceptible to leaching and washing, all samples for which there were data, including the saltcake groups, were considered. The individual PSDs for the waste groups differ from each other to a greater extent after treatment than before. The Group 3/4 Mixture in Figure 3.2 and $5^{\text {th }}$ percentile PSD in Figure 3.1 have relatively equivalent PSDs, but the Group 1/2 Mixture PSD is noticeably smaller than all of the PSDs in Figure 3.1. Because a slurry with the smallest PSD is least likely to plug a breach, the Group 1/2 Mixture was judged a conservative and appropriate PSD to consider for spray leak behavior from treated waste.

In the subsections below, the specific simulant materials that were blended to match these representative PSDs are described.

\subsubsection{Typical As-Received (TAR) Hanford Waste Simulant}

Table 3.3 shows the target PSD for TAR simulant, which is the sludge composite PSD shown in Figure 3.1, together with the PSD of the $8 \mathrm{wt} \%$ TAR simulant. The PSDs of the target, the $8 \mathrm{wt} \% \mathrm{TAR}$, and the $20 \mathrm{wt} \%$ TAR simulant are also shown in Figure 3.3. The simulant PSDs were measured under conditions of flow and sonication. The solid phase in the TAR simulant was Almatis Hydrated Alumina Ath C333 gibbsite. The simulant particles are larger than the target over the lower $95 \%$ of the volume, but appear to contain less of the large $(>100 \mu \mathrm{m})$ particles found in the largest $5 \%$ of the target volume. The largest particle measured was $56 \mu \mathrm{m}$, which was smaller than the target maximum of $792 \mu \mathrm{m}$. 


\begin{tabular}{|c|c|c|}
\hline$\longrightarrow$ AW-103 & $\longrightarrow A Y-101$ & $\longrightarrow$ AY-102 \\
\hline AZ-101 & $A Z-102$ & B-203 \\
\hline$C$ C-104 & C-106 & C-107 \\
\hline S-107 & - SX-108 & $-s Y-102$ \\
\hline$-\mathrm{T}-110$ & $\longrightarrow \mathrm{T}-203$ & $\longrightarrow \mathrm{T}-204$ \\
\hline $1 \mathrm{C}$ and $2 \mathrm{C}$ sludge (M12 Group 1) & CWP1 and CWP2 sludge (M12 Group 3) & CWR1 sludge (M12 Group 4) \\
\hline$\longrightarrow$ — Sludge Composite, Flowing Sonicated & ——5th percentile by UDS volume & $\longrightarrow$ —95th percentile by UDS volume \\
\hline
\end{tabular}

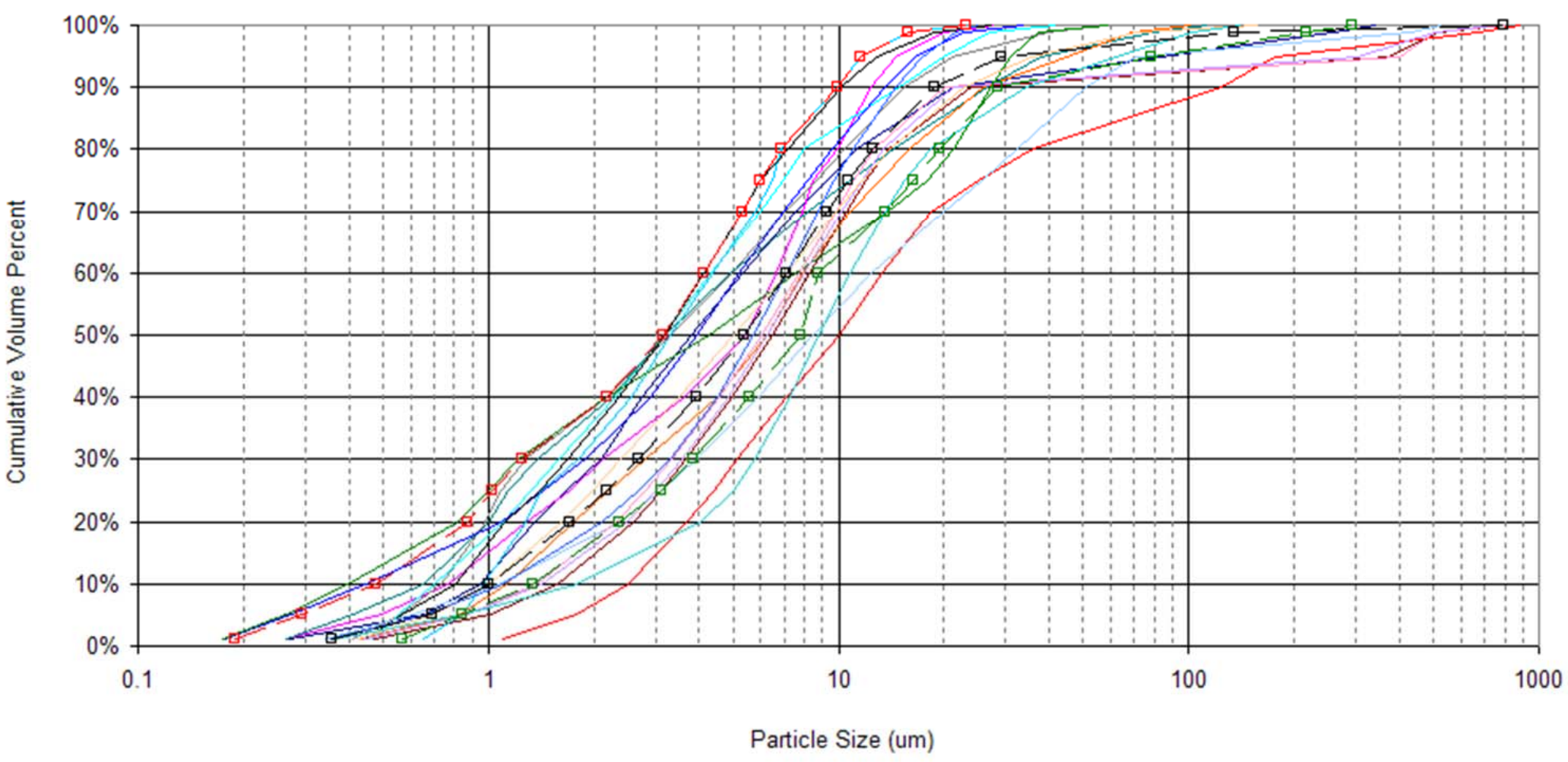

Figure 3.1. Cumulative PSDs (Flowing-Sonicated) for Sludge Tanks and Waste Groups and for 5th Percentile, Sludge Composite (typical), and 95th Percentile PSDs by UDS Volume 


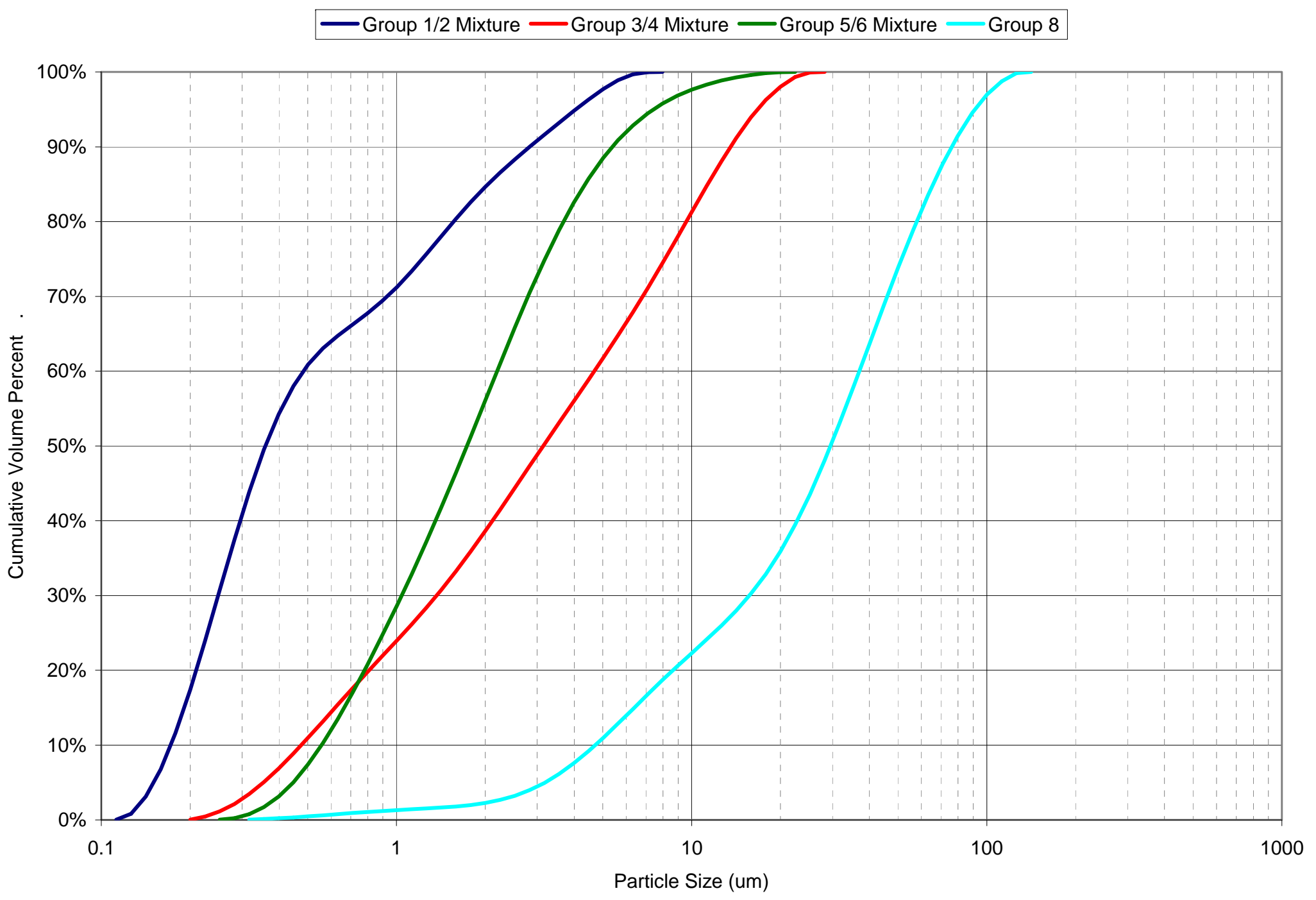

Figure 3.2. Flowing Sonicated PSDs for Post-Caustic Leached and Washed Waste (exception: Group 8 was measured using Flowing Unsonicated instrument settings) 
Table 3.3. TAR Simulant PSD Compared to Target Sludge Composite Combined PSD

\begin{tabular}{ccc}
\hline Percentile & $\begin{array}{c}\text { Target PSD } \\
(\mu \mathrm{m})\end{array}$ & $\begin{array}{c}\text { PSD of Sonicated } \\
8 \mathrm{wt} \% \text { TAR Simulant } \\
(\mu \mathrm{m})\end{array}$ \\
\hline 0.01 & 0.36 & 0.66 \\
0.05 & 0.69 & 1.2 \\
0.10 & 1.0 & 1.7 \\
0.20 & 1.7 & 3.0 \\
0.25 & 2.2 & 3.8 \\
0.30 & 2.7 & 4.6 \\
0.40 & 4.0 & 6.3 \\
0.50 & 5.4 & 8.4 \\
0.60 & 7.1 & 11 \\
0.70 & 9.2 & 14 \\
0.75 & 11 & 16 \\
0.80 & 13 & 18 \\
0.90 & 19 & 25 \\
0.95 & 29 & 31 \\
0.99 & 135 & 43 \\
1 & 792 & 56 \\
\hline
\end{tabular}

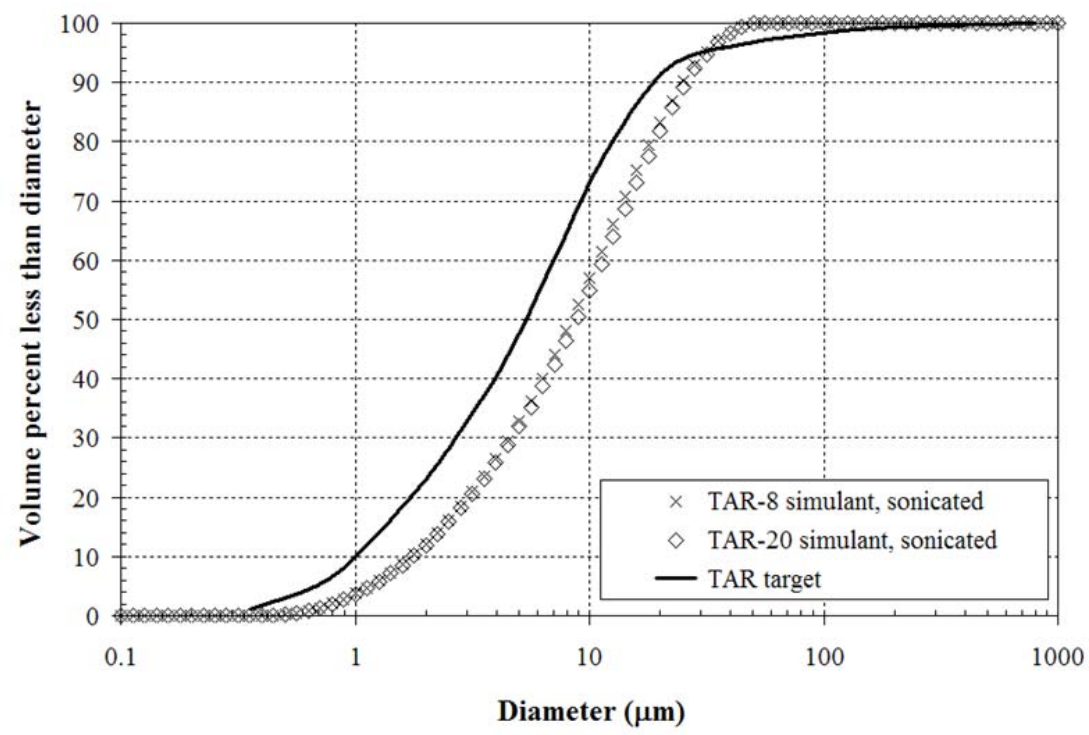

Figure 3.3. TAR Simulant PSD at Two Concentrations and Target Sludge Composite Combined PSD

The $8 \mathrm{wt} \%$ TAR simulant was found to exhibit a Newtonian rheology with a viscosity of $1.2 \mathrm{mPa} \cdot \mathrm{s}$ $(1.2 \mathrm{cP})$. The $20 \mathrm{wt} \%$ simulant was also essentially Newtonian: the Bingham yield stress was $0.05 \mathrm{~Pa}$ (very close to the detection limit of the instrument) and the consistency ${ }^{1}$ was $1.6 \mathrm{cP}$.

${ }^{1}$ In some of the literature, this property is referred to as "plastic viscosity." 


\subsubsection{Small As-Received (SAR) Hanford Waste Simulant}

Table 3.4 shows the target PSD for SAR simulant, which was the 5th percentile PSD shown in Figure 3.1, together with the PSD of the $8 \mathrm{wt} \%$ SAR simulant. The PSDs of the target, the $8 \mathrm{wt} \% \mathrm{SAR}$ simulant, and the $20 \mathrm{wt} \%$ SAR simulant, are also shown in Figure 3.4. The simulant PSDs were measured under conditions of flow and sonication. The solid phase in the simulant was a mixture of $35 \%$ NOAH R6011 gibbsite and 65\% Nabaltec APYRAL 40CD gibbsite. The simulant contains larger particles than the target over a portion of the volume, including the largest particles which are expected to have the most impact on orifice plugging.

The $8 \mathrm{wt} \%$ SAR simulant was found to be essentially Newtonian: the Bingham yield stress was $0.05 \mathrm{~Pa}$ (very close to the detection limit of the instrument) and the consistency was $1.6 \mathrm{mPa} \cdot \mathrm{s}$. At the higher solids concentration, $20 \mathrm{wt} \%$, the Bingham yield stress was $0.91 \mathrm{~Pa}$ and the consistency was $3.0 \mathrm{mPa} \cdot \mathrm{s}$.

Table 3.4. SAR Simulant PSD Compared to Target 5th Percentile PSD Weighted by UDS Volume

\begin{tabular}{ccc}
\hline & $\begin{array}{c}\text { Target PSD } \\
(\mu \mathrm{m})\end{array}$ & $\begin{array}{c}\text { PSD of Sonicated } 8 \mathrm{wt} \% \\
\text { SAR Simulant } \\
(\mu \mathrm{m})\end{array}$ \\
\hline 0.01 & 0.19 & 0.67 \\
0.05 & 0.29 & 0.94 \\
0.10 & 0.48 & 1.2 \\
0.20 & 0.88 & 1.6 \\
0.25 & 1.0 & 1.8 \\
0.30 & 1.2 & 2.0 \\
0.40 & 2.2 & 2.4 \\
0.50 & 3.2 & 3.0 \\
0.60 & 4.1 & 3.7 \\
0.70 & 5.3 & 4.9 \\
0.75 & 6.0 & 6.0 \\
0.80 & 6.9 & 7.8 \\
0.90 & 10 & 14 \\
0.95 & 12 & 19 \\
0.99 & 16 & 27 \\
1 & 23 & 40 \\
\hline
\end{tabular}




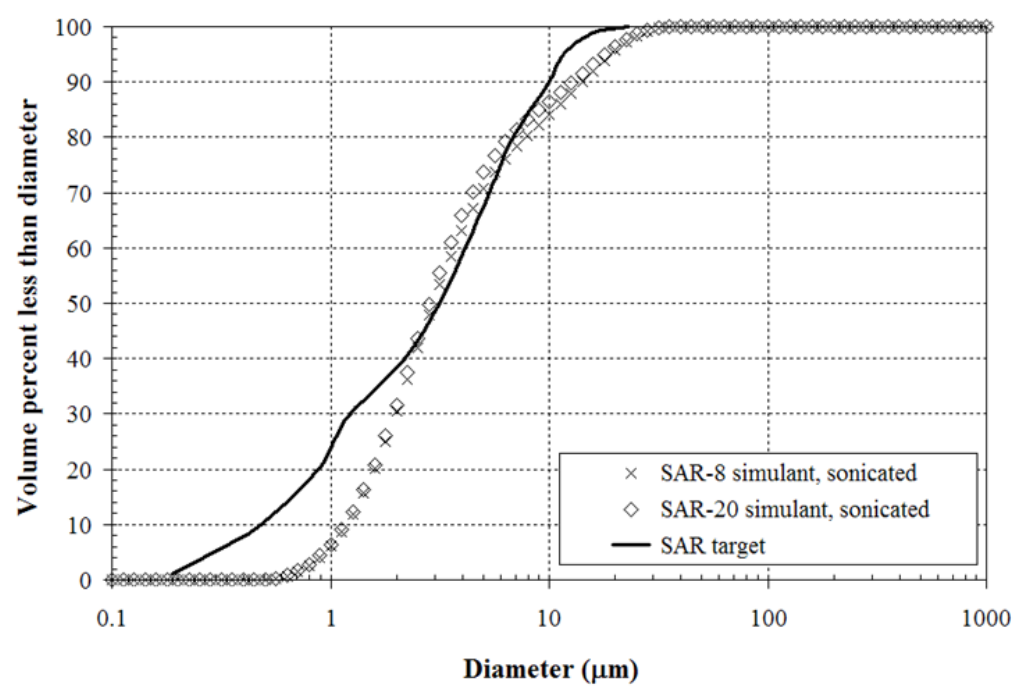

Figure 3.4. SAR Simulant PSD at Two Concentrations and Target $5^{\text {th }}$ Percentile PSD

\subsubsection{Small Treated (STR) Hanford Waste Simulant}

Table 3.5 shows the target PSD for STR simulant, which was the Group 1/2 PSD shown in Figure 3.2, together with the PSD of the $8 \mathrm{wt} \%$ STR simulant. The PSDs of the target, the $8 \mathrm{wt} \% \mathrm{STR}$ simulant, and the $20 \mathrm{wt} \%$ STR simulant, are also shown in Figure 3.5. The simulant PSDs were measured under conditions of flow and sonication. The solid phase in the simulant was a mixture of $80 \%$ Nabaltec APYRAL AOH60 boehmite and 20\% NOAH R6000 boehmite. The simulant contains larger particles than the target over much of the volume including the largest particles which are expected to have the most impact on orifice plugging.

The $8 \mathrm{wt} \%$ STR simulant had a Bingham yield stress of $1.4 \mathrm{~Pa}$ and a consistency of $3.0 \mathrm{mPa} \cdot \mathrm{s}$. At the higher concentration, $20 \mathrm{wt} \%$, the simulant appeared to be a Newtonian fluid with a viscosity of $1.5 \mathrm{mPa} \cdot \mathrm{s}$. This is contrary to the expected behavior in which increasing solids concentrations lead to more non-Newtonian rheological behavior. These results were confirmed by analyzing replicate aliquots of the simulant feed. After testing had been completed, a fresh STR simulant sample was produced and characterized. Samples of this simulant showed Newtonian behavior for both $8 \%$ and $20 \%$ simulants, with viscosities of 1.3 and $1.5 \mathrm{mPa} \cdot \mathrm{s}$ respectively. The non-Newtonian behavior of the early samples of $8 \mathrm{wt} \%$ STR is not understood. 
Table 3.5. STR Simulant PSD Compared to Target Group 1/2 Mixture Flowing Sonicated Combined PSD

\begin{tabular}{ccc}
\hline Percentile & $\begin{array}{c}\text { Target PSD } \\
(\mu \mathrm{m})\end{array}$ & $\begin{array}{c}\text { PSD of Sonicated } \\
8 \mathrm{wt} \% \text { STR Simulant } \\
(\mu \mathrm{m})\end{array}$ \\
\hline 0.01 & 0.13 & 0.31 \\
0.05 & 0.15 & 0.40 \\
0.25 & 0.23 & 0.67 \\
0.50 & 0.36 & 0.98 \\
0.75 & 1.2 & 1.5 \\
0.95 & 4.1 & 2.9 \\
0.99 & 5.7 & 8.8 \\
1 & 8.0 & 20 \\
\hline
\end{tabular}

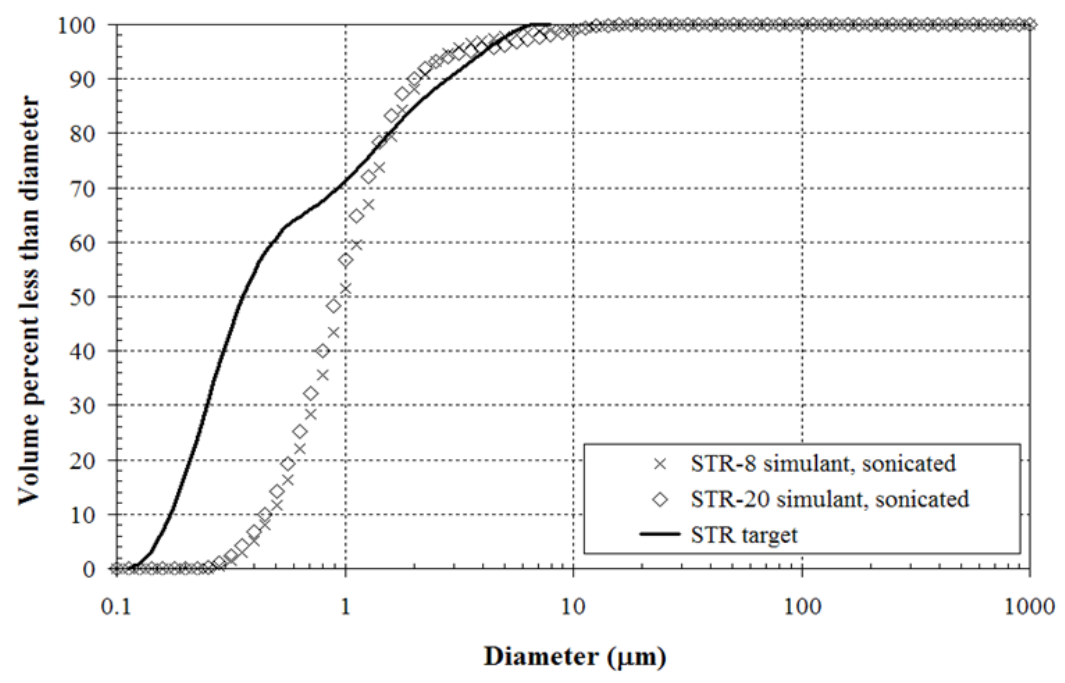

Figure 3.5. STR Simulant PSD at Two Concentrations and PSD of Target Group 1/2 Mixture

\subsubsection{Additional Simulants Considered for Plugging Tests}

The test plan included testing of two simulants that were not tested. One of these simulants was the large as-received (LAR) simulant which targeted the $95^{\text {th }}$ percentile PSD shown in Figure 3.1. No plugging tests with the LAR simulant were necessary because simulants with smaller particles resulted in some plugging of the smallest orifice tested. The originally-planned plugging tests involving the non-Newtonian washed and leached chemical slurry simulant were to have been performed together with the small-scale spray aerosol tests. Plugging tests with this simulant were not completed because the aerosol test results indicated that the smaller orifices did not result in an overall increase in aerosol generation. Since the bounding releases for the WTP hazards analysis involves larger orifices there was little value in completing these tests. 


\subsubsection{Summary of Measured Simulant Properties}

For convenience, Table 3.6 provides a summary of the measured properties of the simulants used in the plugging tests.

Table 3.6. Summary of Measured Simulant Properties

\begin{tabular}{|c|c|c|c|c|c|c|}
\hline \multirow[b]{2}{*}{ Simulant } & \multicolumn{4}{|c|}{ Particle Sizes $(\mu \mathrm{m})$ by Volume Percentile } & \multicolumn{2}{|c|}{ Rheological Properties } \\
\hline & $10^{\text {th }}$ & $50^{\text {th }}$ & $90^{\text {th }}$ & $100^{\text {th }}$ & $\begin{array}{c}\text { Bingham yield } \\
\text { stress } \\
(\mathrm{Pa})\end{array}$ & $\begin{array}{l}\text { Bingham } \\
\text { consistency } \\
(\mathrm{mPa} \cdot \mathrm{s})\end{array}$ \\
\hline SAR-8 & 1.2 & 3.0 & 14 & 40 & 0.1 & 1.6 \\
\hline SAR-20 & 1.2 & 2.8 & 13 & 40 & 0.9 & 3.0 \\
\hline TAR-8 & 1.7 & 8.4 & 25 & 56 & 0 & 1.2 \\
\hline TAR-20 & 1.8 & 8.8 & 26 & 56 & 0.1 & 1.6 \\
\hline STR-8 (batch used in test feed) & 0.48 & 0.98 & 2.2 & 20 & 1.4 & 3.0 \\
\hline STR-8 (later batch) & $\mathrm{n} / \mathrm{m}$ & $\mathrm{n} / \mathrm{m}$ & $\mathrm{n} / \mathrm{m}$ & $\mathrm{n} / \mathrm{m}$ & 0 & 1.3 \\
\hline STR-20 (batch used in test feed) & 0.45 & 0.91 & 2.0 & 16 & 0 & 1.5 \\
\hline STR-20 (later batch) & $\mathrm{n} / \mathrm{m}$ & $\mathrm{n} / \mathrm{m}$ & $\mathrm{n} / \mathrm{m}$ & $\mathrm{n} / \mathrm{m}$ & 0 & 1.5 \\
\hline
\end{tabular}

The properties listed in Table 3.6, and discussed in the rest of Chapter 3, were measured in samples taken from the feed tank before the first test in which the simulant was used. They do not account for any effects of testing. The effect of testing on the PSDs is discussed in Section 6.1.

\subsection{Simulant Makeup}

All of the simulants used in plugging tests were made up using the same procedure. ${ }^{1}$ The required solids were weighed out on calibrated scales, added to tap water, and mixed. After all solids were added, the slurry was blended for a minimum of 30 minutes in a nominal 100-gal stainless steel vessel, blended in this vessel, sampled, then stored until needed for testing. When simulants were removed from storage, they were mechanically mixed before transferring them to the feed vessel in the plugging test apparatus. Table 3.7 gives the masses of solid components and water that were used to produce batches of each of the plugging test simulants.

\footnotetext{
${ }^{1}$ The simulant makeup procedure for this purpose was governed by TI-WTPSP-040, "Simulant Blending to Support Small-Scale Spray Testing."
} 
Table 3.7. Masses of Components for Simulant Batches for Plugging Tests

\begin{tabular}{|c|c|c|c|c|c|c|}
\hline \multirow[b]{2}{*}{ Component } & \multicolumn{2}{|c|}{$\begin{array}{c}\text { Small } \\
\text { Treated } \\
\text { (STR) }\end{array}$} & \multicolumn{2}{|c|}{$\begin{array}{c}\text { Small } \\
\text { As-Received } \\
\text { (SAR) }\end{array}$} & \multicolumn{2}{|c|}{$\begin{array}{c}\text { Typical } \\
\text { As-Received } \\
\text { (TAR) }\end{array}$} \\
\hline & $8 w t^{0}{ }^{(a)}$ & $20 \mathrm{wt} \%$ & $8 \mathrm{wt} \%$ & $20 \mathrm{wt} \%$ & $8 \mathrm{wt} \%$ & $20 \mathrm{wt} \%$ \\
\hline Almatis Hydrated Alumina Ath C333 gibbsite (kg) & --- & --- & --- & --- & 12.710 & 34.247 \\
\hline Nabaltec APYRAL 40CD gibbsite $(\mathrm{kg})$ & --- & --- & 8.245 & 22.261 & --- & --- \\
\hline Nabaltec APYRAL AOH60 boehmite (kg) & 20.433 & 27.909 & --- & --- & --- & --- \\
\hline NOAH R6000 boehmite (kg) & 5.108 & 6.977 & --- & --- & --- & --- \\
\hline NOAH R6011 gibbsite (kg) & --- & --- & 4.440 & 11.987 & --- & --- \\
\hline Tap water $(\mathrm{kg})$ & 293.726 & 139.546 & 145.882 & 136.990 & 146.160 & 136.990 \\
\hline
\end{tabular}





\subsection{Equipment Description}

Plugging tests were conducted in an enclosure, using a test loop that allowed recirculating flow of slurries and liquids at constant flow rate and pressure for a range of leak orifices. Each individual test was defined by a set of orifices (up to four), one pressure, and a selected slurry simulant. When possible, multiple orifices were evaluated simultaneously to increase operational efficiency. Temperature, pressure, and flow rate signals were recorded by a data logger. The time at which the leak plugged (if it plugged) was judged based on visual observations. Simulant samples were taken and evaluated for changes in the PSD.

The test equipment, the instruments used in collecting data related to plugging, and the instruments used in measuring orifice sizes are described in Section 4.2, Section 4.3, and Section 4.4, respectively.

\subsection{Test Loop}

The small-scale test loop was located in and adjacent to the walk-in hood in room 107 of the Applied Process Engineering Laboratory. Each simulant used in the test was prepared in a secondary tank and was transferred into the system feed tank using a diaphragm pump. The test loop is depicted in the schematic diagram in Figure 4.1. Simulant was circulated from the feed tank, through the pump, into the horizontal test header, and back to the feed tank. The feed tank was mixed at all times during a test.

One to four leak orifices were located on the portion of the header that was within the test enclosure, allowing plugging to be tested in more than one orifice at a time. Each orifice was part of a test piece that could be swapped for other orifice test pieces (OTPs) or for blanks, as shown in Figure 4.2. The OTPs had a wall thickness equal to that of 3 -in. Schedule 40 pipe, providing a leak-path length equal to that in the large-scale test equipment and in much of the piping in the WTP equipment. The inner surface of each OTP was flush with the inner wall of the pipe.

The jets from the orifices were aimed horizontally along the length of the enclosure, as reasonably achievable. Figure 4.3 is a drawing of the enclosure; the header was located at the left end of the enclosure. The sloped bottom directed the collected spray to the drain near the right end.

The small-scale test system included not only the test loop but a bypass header. The bypass header allowed the simulant to be recirculated while the system was brought to the desired flow rate and pressure. Upon initiating a spray, the bypass header was closed. Manually controlled flow control valves were used to maintain the designated test pressure in the test header.

The test header was Swagelok tubing with a nominal outer diameter of $1.0 \mathrm{in} .(2.54 \mathrm{~cm})$ and a nominal wall thickness of $0.065 \mathrm{in} .(0.165 \mathrm{~cm})$. A flow rate of approximately $10 \mathrm{gpm}(5.4 \mathrm{ft} / \mathrm{s})$ through the test header was calculated to provide the same wall shear stress within about 10 percent as would be present in a 3-in. Schedule 40 pipe with a flow velocity of $6.5 \mathrm{ft} / \mathrm{s}$. The latter flow velocity and pipe size were typical of the smaller lines in the WTP equipment and were used in the test header for the large-scale tests, so the approximate matching of wall shear stress provided consistent conditions for the orifice entry point between the two test scales. Most of the tests were conducted with recirculating flow past the orifice but a limited number of tests were conducted in a dead-end configuration with the end of the OTP capped. The simulants for which the approximately matched-shear-stress criterion could be met 
were Newtonian simulants and non-Newtonian simulants with Bingham yield stress of $6 \mathrm{~Pa}$ or less and Bingham consistency of $6 \mathrm{mPa} \cdot \mathrm{s}$ or less.

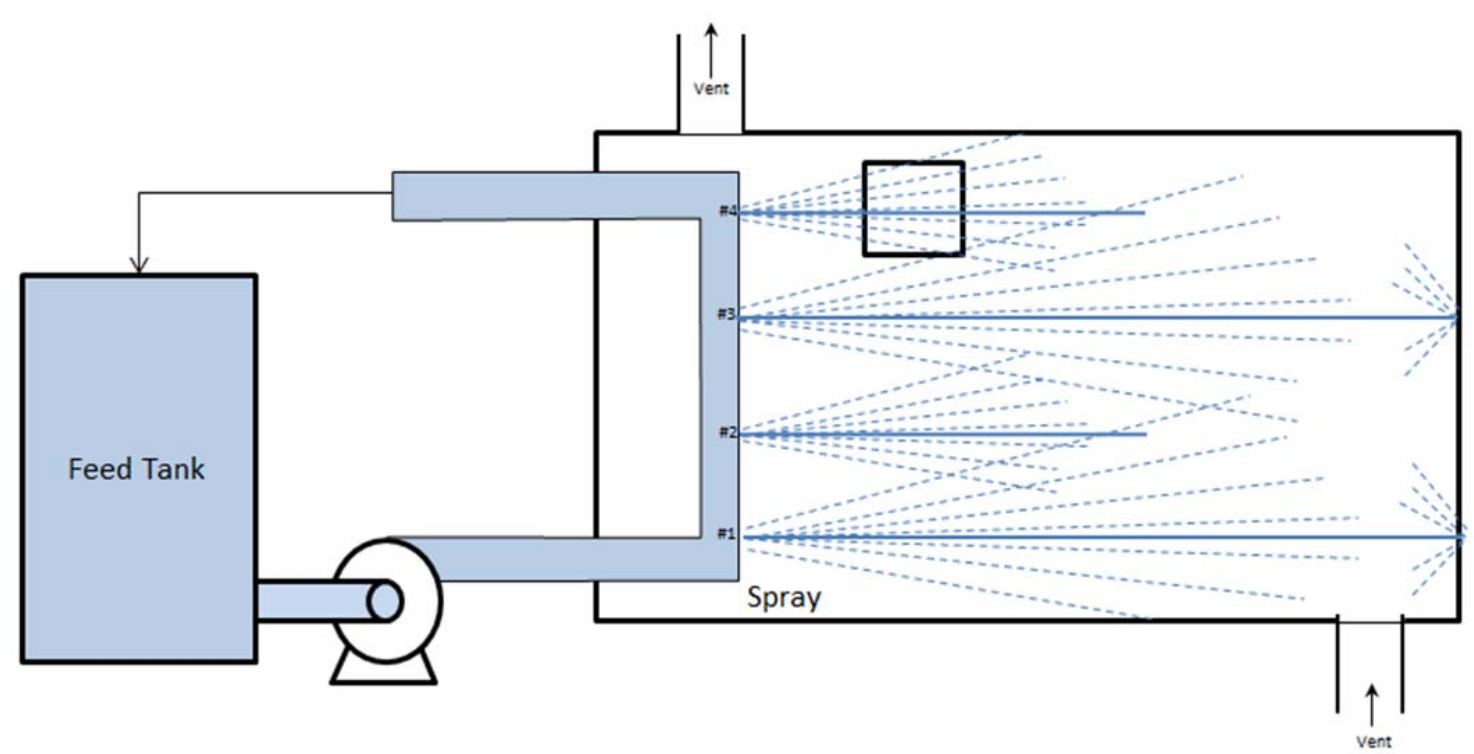

Figure 4.1. Schematic of Small Scale Testing System (the spray test section is horizontal relative to enclosure)

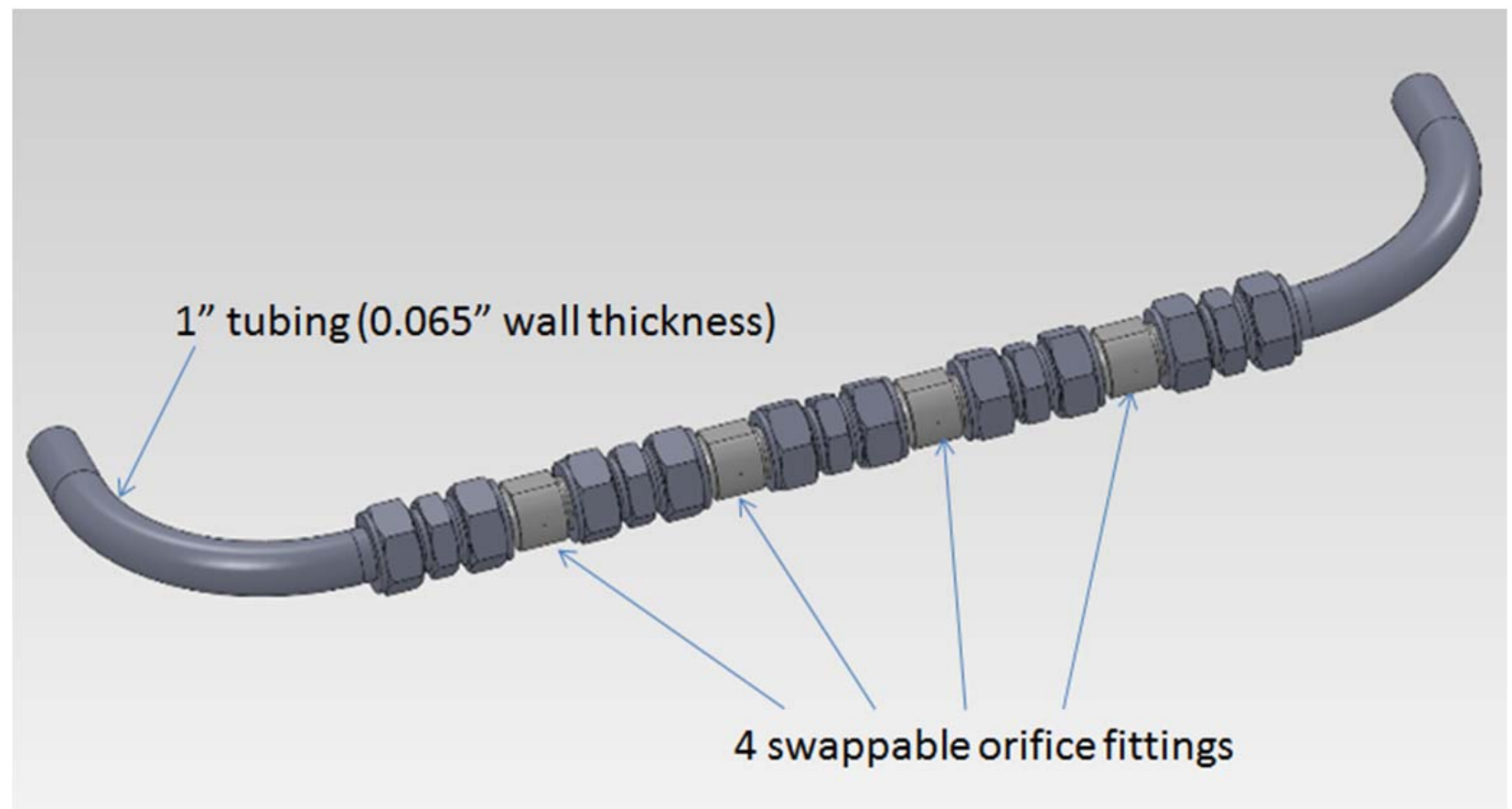

Figure 4.2. Design of Interchangeable Test Section 


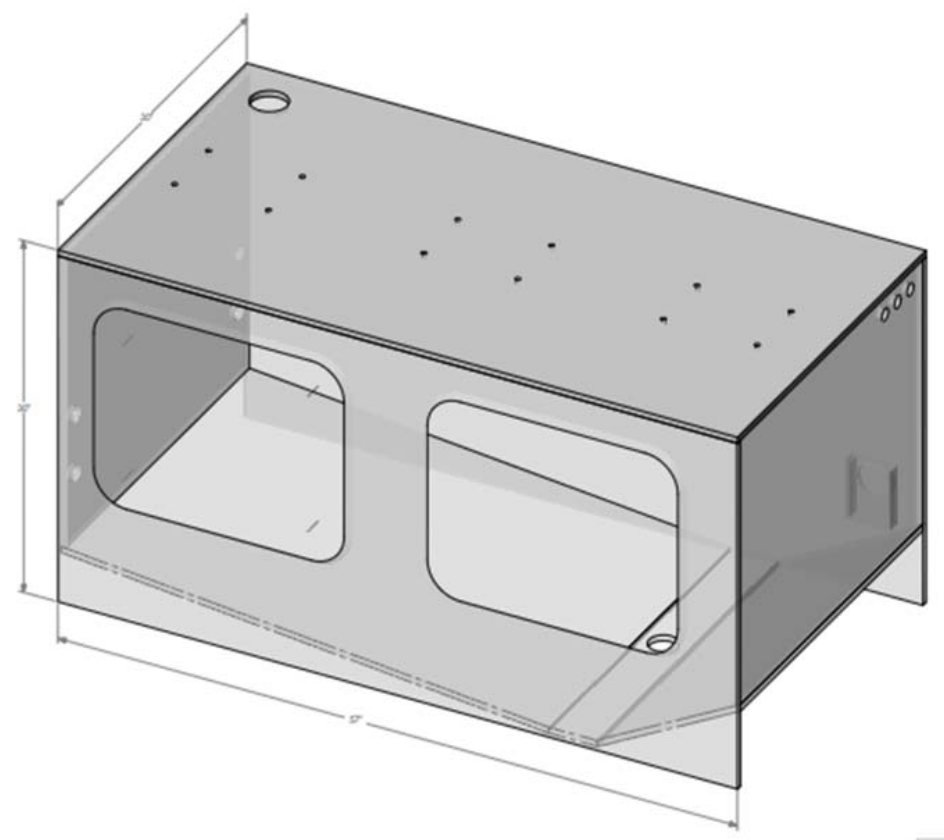

Figure 4.3. Enclosure for Small-Scale Testing

For most of the plugging tests, a feed volume of 40 gal or less was adequate and recycling simulant from the enclosure back into the feed tank was not necessary. For some of the larger orifices, it was necessary to transfer simulant, while spraying, back into the feed vessel using a diaphragm pump.

The overall dimensions of the enclosure were about 30 " wide x 30 " high x 57" long. As shown in Figure 4.3, the enclosure had windows in appropriate locations for viewing sprays, including multiple simultaneous sprays. The test header elevation was halfway between the floor and the greatest height of the enclosure.

\subsection{Test System Data Collection and Instruments}

A calibrated data logger, connected to a PC, was used to collect temperature data and raw voltages that could be translated, using the instrument calibration data, into the appropriate units for the measured data. The time, temperature, and voltage data were saved as Excel spreadsheet files. Table 4.1 lists the instruments that were used to collect data to support the test data analysis.

Table 4.1. Instruments Used in Plugging Tests

\begin{tabular}{|c|c|c|}
\hline Instrument Name & Measurement & Calibrated Range \\
\hline $\begin{array}{l}\text { Micromotion Coriolis } \\
\text { Mass Flow Sensor }\end{array}$ & $\begin{array}{l}\text { Flow rate in test header; connected to } \\
\text { data logger }\end{array}$ & $0-35$ gpm \\
\hline $\begin{array}{l}\text { Honeywell Pressure } \\
\text { Transmitter }\end{array}$ & $\begin{array}{l}\text { Pressure in test header upstream of the } \\
\text { OTPs; connected to data logger }\end{array}$ & $0-500$ psig \\
\hline $\begin{array}{l}\text { Honeywell Pressure } \\
\text { Transmitter }\end{array}$ & $\begin{array}{l}\text { Pressure in test header downstream of } \\
\text { the OTPs; connected to data logger }\end{array}$ & $0-500$ psig \\
\hline Thermocouple & $\begin{array}{l}\text { Temperature in test header; connected } \\
\text { to data logger }\end{array}$ & $31-120^{\circ} \mathrm{F}$ \\
\hline
\end{tabular}




\subsection{Orifice Imaging Hardware and Software}

The sizes of the orifices used in the plugging tests were measured using an imaging system comprised of a digital camera and lens. The camera used was an Edmund Optics EO-1918C, with image size of 1600 pixels horizontal by 1200 pixels vertical. An InfiniGage CW lens and lens spacers, also available from Edmund Optics, were attached to the camera, and images were captured with StreamPix software, version 5.3.0. An MR-1 Micro-Ruler supplied by Geller MicroAnalytical Laboratory Inc. was also used, which was calibrated per QA requirements.

\subsection{Orifice Dimensions}

The dimensions of the orifices that were used in the plugging tests are given in Table 4.2. These dimensions were measured where the orifice intersects the outer diameter of the pipe as shown in Figure 4.4, which is the exit point for the spray traveling through the orifice passage. Attempts to determine the dimensions of the orifice where it intersects the inner diameter of the pipe, while viewing from the outer diameter, were unsuccessful. This was largely due to the small orifices acting as pinhole lenses, producing a falsely magnified image of the inner-diameter orifice size. This only impacted orifice dimensions smaller than $1 \mathrm{~mm}$. Alternative methods to obtain inner end dimensions produced unreliable results, and destructive methods of examination were generally not pursued due to the need for the OTPs throughout testing. The exception was the smallest orifice with a target diameter of $0.2 \mathrm{~mm}$. In this case a hole was drilled through the OTP to allow examination of the orifice diameter at the inner pipe wall. The smaller orifices generally have a smaller diameter on the inside of the OTP than on the outside. This is due to the nature of the fabrication technique. The depth of the orifices (length of the passage) was within $10 \%$ of the thickness of 3" Schedule 40 pipe, 0.216 in. The orifice depth-to-diameter ratio is also provided in Table 4.2 and is based on the pipe wall thickness. For the two slots, the ratio is provided as the orifice depth:width.

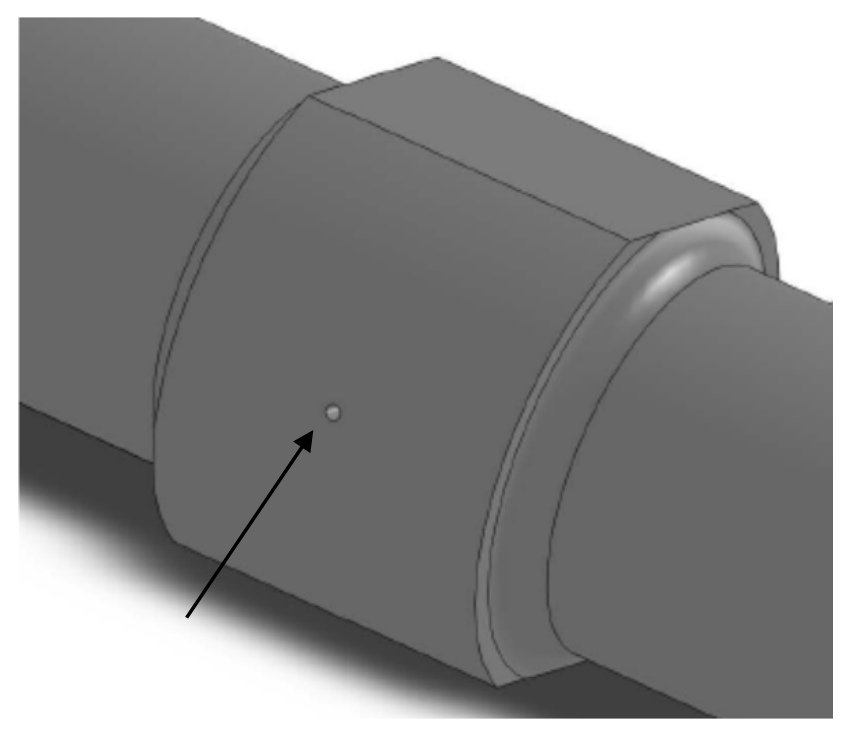

Figure 4.4. Orifice Images Measured Where Orifice Intersects With Outer Diameter of Pipe 
Table 4.2. Dimensions for the Orifices Used

\begin{tabular}{lccccc}
\hline $\begin{array}{c}\text { Orifice } \\
\text { Designation }\end{array}$ & $\begin{array}{c}\text { Exit Diameter or } \\
\text { Length } x \text { Width } \\
(\mathrm{mm})\end{array}$ & $\begin{array}{c}\text { Pipe Wall } \\
\text { Thickness } \\
\text { (in) }\end{array}$ & $\begin{array}{c}\text { Orifice } \\
\text { Depth:Diameter } \\
\text { or Depth:Width }\end{array}$ & $\begin{array}{c}\text { Inner Diameter or } \\
\text { Length } \mathrm{x} \text { Width } \\
(\mathrm{mm})\end{array}$ & Type \\
\hline OTP-01 & 0.245 & 0.2056 & 21.3 & 0.188 & Round \\
OTP-02 & 0.382 & 0.2074 & 13.8 & $\mathrm{n} / \mathrm{m}$ & Round \\
OTP-03 & 0.534 & 0.215 & 10.2 & $\mathrm{n} / \mathrm{m}$ & Round \\
OTP-04 & 0.706 & 0.2157 & 7.8 & $\mathrm{n} / \mathrm{m}$ & Round \\
OTP-07 & $0.260 \times 4.946$ & 0.2134 & 20.8 & $\mathrm{n} / \mathrm{m}$ & Axial slot \\
OTP-34 & $0.357 \times 5.021$ & 0.2184 & 15.6 & & Axial slot \\
\hline $\mathrm{n} / \mathrm{m}=$ Not measured
\end{tabular}

\subsection{Sample Analysis}

Samples were analyzed for size distribution and rheological behavior. Testing was conducted according to RPL-COLLOID-02, Measurement of Physical and Rheological Properties of Solutions, Slurries and Sludges.

The size measurements were made using a Mastersizer 2000 (Malvern Instruments, Inc.) with a Hydro $\mathrm{S}$ wet dispersion accessory. The particle size measurement range was nominally 0.02 to $2000 \mu \mathrm{m}$. The Malvern 2000 uses laser diffraction technology. The Hydro S wet dispersion accessory consisted of a $150-\mathrm{mL}$ sonic dispersion unit coupled with a sample flow cell, allowing the flow, stirring rate, and sonication to be controlled and altered during measurement. PSD measurements were made both with and without sonication. The PSD measurements were conducted with solids dispersed in the sample liquid.

Flow-curve data for rheological behavior were measured using a concentric cylinder rotational viscometer operated in controlled-rate mode. The instrument was an Anton Parr Rheometer (MCR 301) with an MV1 stainless steel measuring cup and rotor. Each flow curve was measured over three intervals. Over the first 5 minutes, the shear rate was smoothly increased from zero to $1000 \mathrm{~s}^{-1}$. For the next minute, the shear rate was held constant at $1000 \mathrm{~s}^{-1}$. For the final 5 minutes, the shear rate was smoothly reduced back to zero. During this time, the resisting torque and rotational rate were continuously monitored and recorded.

More detail about size and flow-curve measurements methods can be found in Sections E.1.2.3 and E.1.2.4 of Kurath et al. (2009). 



\subsection{Test Operations}

The objective of the plugging tests was to determine the sizes of circular and slot-shaped breaches that would consistently plug and not form appreciable sprays with slurry simulants within 15 minutes. The target range of orifice sizes and test pressures that were included in the test matrix are shown in Table 5.1. The range of simulants that were used has been described in Chapter 3 .

The success criteria for plugging tests were to

- visually observe the formation of sprays to determine whether significant breach plugging occurred within an appropriate time (the target was 15 minutes);

- measure the pressure and flow in the piping; and

- characterize the slurry simulant particle size distribution and rheology for each slurry tested.

Section 5.1 details the matrix of tests that were performed to meet the test objective. ${ }^{(1)}$ The testing procedure is described in Section 5.2; one important part of that procedure, the microscopic examination of the orifices, is described in more detail in Section 5.3.

Table 5.1. Ranges of Plugging Test Parameters

\begin{tabular}{|c|c|c|}
\hline Parameter & $\begin{array}{l}\text { Parameter } \\
\text { Range }\end{array}$ & Comments \\
\hline $\begin{array}{l}\text { Pressure } \\
\text { (psig) }\end{array}$ & $100,200,380$ & $\begin{array}{l}200 \text { and } 380 \text { psig are the highest pressures during important } \\
\text { accident scenarios at the Waste Treatment Plant. The acceptable } \\
\text { range was }+/-10 \% \text { of the target setpoint. }\end{array}$ \\
\hline Circular Breach Diameter $(\mathrm{mm})$ & $0.2-1.0$ & The smallest breach size was based on machining limitations. \\
\hline $\begin{array}{l}\text { Rectangular Breach Size }(\mathrm{mm}) \\
\text { (width) } \\
\text { (length) }\end{array}$ & $\begin{array}{l}0.2-0.3 \\
5\end{array}$ & \\
\hline
\end{tabular}

\subsection{Test Matrix}

The sequence of tests was arranged such that the smallest orifices would be tested first. It was possible to test as many as four orifices at a time, if the joint flow rate was not so great as to empty the feed tank in 15 minutes. Once the size of the smallest non-plugging orifice was determined, there was no need to continue testing the same simulant with larger orifices of the same type (round or slot). The simulants with the smallest PSDs - the STR, SAR, and TAR simulants - were tested before deciding whether to test the larger-size LAR simulant. Under the test plan, the latter required testing only if none of the smaller-sized simulants showed any evidence of plugging.

\footnotetext{
${ }^{1}$ The tests were performed under Test Plan TP-WTPSP-031 Rev 0.1, Project Plan PP-WTPSP-033 Rev. 0, Test Instruction TI-WTPSP-036 (for water shakedown tests and slurry tests SS-P-PV1 and SS-P-PV3), and Test Instruction TI-WTPSP-041 (for all other tests).
} 
The test matrix is given in Table 5.2 and the simulant aliases are given in Table 5.3. The test naming convention was SS-P-@\#-\#\#\#, where SS-P indicates small-scale plugging, -@ indicates the objective of the individual test (i.e., $\mathrm{PV}=$ pressure variation, $\mathrm{S}=$ simulant evaluation, $\mathrm{SO}=$ slot orifice size variation, etc.), \# indicates the overall plugging test number from 1 to $\mathrm{N}$ (where $\mathrm{N}$ is the sequential test number), and \#\#\# indicates the test pressure. In some cases an R\# is appended to the test name. This indicates that a retest was conducted and the number indicates the sequential retest number. Unless otherwise noted, slot orifices were oriented axially (along the direction of flow).

The originally-planned plugging tests involving non-Newtonian Fe-rich (FER) simulants were initially postponed because of delayed simulant availability. The FER plugging tests were to be performed together with the small-scale spray aerosol tests. Eventually, the plugging tests with the FER series of simulants were canceled because the aerosol results indicated that the smaller orifice did not result in an overall increase in aerosol generation. Since the bounding releases for the WTP hazards analysis involves larger orifices there was little value in completing these tests.

Table 5.2. Matrix of Plugging Tests

\begin{tabular}{|c|c|c|c|c|}
\hline Test Number & $\begin{array}{l}\text { Orifice Size(s) } \\
(\mathrm{mm})\end{array}$ & $\begin{array}{c}\text { Pressure } \\
\text { (psig) }\end{array}$ & Simulant & $\begin{array}{c}\text { Purpose/ } \\
\text { Comments }\end{array}$ \\
\hline \multicolumn{5}{|l|}{ Pressure Variation (PV) } \\
\hline $\begin{array}{l}\text { SS-P-PV1-380 } \\
\text { SS-P-PV1-200 } \\
\text { SS-P-PV1-100 }\end{array}$ & $0.245,0.382,0.534,0.706$ & $\begin{array}{l}383 \\
203 \\
100\end{array}$ & $\begin{array}{l}\text { STR, } \\
8 \mathrm{wt} \%\end{array}$ & $\begin{array}{l}\text { Evaluate pressure influence } \\
\text { on plugging with baseline } \\
\text { simulant }\end{array}$ \\
\hline $\begin{array}{l}\text { SS-P-PV3-380 } \\
\text { SS-P-PV3-200 } \\
\text { SS-P-PV3-100 }\end{array}$ & $0.260 \times 4.946,0.357 \times 5.021$ & $\begin{array}{l}380 \\
201 \\
99.7\end{array}$ & & \\
\hline \multicolumn{5}{|l|}{ Simulant (S) } \\
\hline SS-P-S7-380 & $0.245,0.382,0.534,0.706$ & 382 & STR, & \multirow{8}{*}{$\begin{array}{l}\text { Evaluate simulant } \\
\text { influence on plugging with } \\
\text { varying simulants }\end{array}$} \\
\hline SS-P-S9-380 & $0.260 \times 4.946,0.357 \times 5.021$ & 381 & $20 \mathrm{wt} \%$ & \\
\hline $\begin{array}{l}\text { SS-P-S13-380 } \\
\text { SS-P-S13-100 }\end{array}$ & $0.245,0.382,0.534,0.706$ & $\begin{array}{l}380 \\
100\end{array}$ & $\begin{array}{l}\text { SAR, } \\
8 \mathrm{wt} \%\end{array}$ & \\
\hline $\begin{array}{l}\text { SS-P-S19-380-R2 } \\
\text { SS-P-S19-200 }\end{array}$ & $0.245,0.382,0.534,0.706$ & $\begin{array}{l}380 \\
201\end{array}$ & $\begin{array}{l}\text { SAR, } \\
20 \mathrm{wt} \%\end{array}$ & \\
\hline SS-P-S25-380 & $0.245,0.382,0.534,0.706$ & 381 & TAR, & \\
\hline SS-P-S27-380 & $0.260 \times 4.946,0.357 \times 5.021$ & 381 & $8 \mathrm{wt} \%$ & \\
\hline SS-P-S31-380 & $0.245,0.382,0.534,0.706$ & 380 & TAR, & \\
\hline SS-P-S33-380 & $0.260 \times 4.946,0.357 \times 5.021$ & 382 & $20 \mathrm{wt} \%$ & \\
\hline \multicolumn{5}{|l|}{ Slot Orientation (SO) } \\
\hline SS-P-SO48-380 & 0.245 (dead-end) & 380 & STR, & Effect of flow orientation \\
\hline SS-P-SO48-380-300 ${ }^{(\mathrm{a})}$ & 0.382 (dead-end) & 380 & $8 \mathrm{wt} \%$ & by the orifice \\
\hline
\end{tabular}

(a) The -300 refers to the nominal orifice size which was $0.382 \mathrm{~mm}$. 
Table 5.3. Simulant Nomenclature

\begin{tabular}{lcl}
\hline Simulant Description & Alias & Comments \\
\hline Small Treated Hanford Waste PSD & STR & $\begin{array}{l}\text { Primary simulant. No anti-foam agent (AFA) } \\
\text { unless otherwise stated. }\end{array}$ \\
Small as-received Hanford Waste PSD & SAR & $\begin{array}{l}\text { No AFA unless otherwise stated. } \\
\begin{array}{l}\text { Typical as-received Hanford Waste PSD } \\
\text { Large as-received Hanford Waste PSD }\end{array}\end{array}$ \\
$\begin{array}{lll}\text { Washed and Leached Chemical Slurry Simulant } \\
\text { (non-Newtonian) }\end{array}$ & LAR & $\begin{array}{l}\text { No AFA unless otherwise stated. } \\
\text { No AFA unless otherwise stated. The LAR } \\
\text { simulant was not tested. }\end{array}$ \\
\hline
\end{tabular}

\subsection{Plugging Test Procedure}

The plugging test procedure was developed to support plugging observations, ensure they were made under well-characterized conditions, and maintain staff safety and equipment operability. The procedure is summarized here.

Each test began by verifying the system configuration and condition and confirming that the test conditions and the simulant were those required for the test. The feed tank platform scale was checked for zero weight, if the feed tank was empty, or was used to measure the weight of simulant, if there was a batch in the tank. If the weight had decreased since the last weighing, water was assumed to have evaporated and tap water was added to make up the difference.

If there was a need to fill the feed tank with simulant that was not the same type as the last batch tested, the first step was to confirm that the tank and flow system had been cleaned. Then the agitator in the transfer tank was turned on, using the maximum speed that did not entrain air or create a vortex. After at least 30 seconds of agitation and recirculation, the diaphragm pump was used to transfer the batch of simulant to the feed tank. In some cases the simulant, as received, did not contain the full amount of liquid because several gallons had been reserved as rinse liquid. In these cases, the reserved liquid was used to rinse the transfer tank, and this material was also transferred to the feed tank. As the transfer proceeded, the agitator speed in the transfer tank was decreased and that in the feed tank was increased, always taking care to avoid air entrainment and vortices. When the feed tank was filled, the weight of the simulant in it was measured. The hood vacuum supply was used to prime the test system pump and lines by drawing in slurry from the feed tank. Simulant was then circulated through the system lines until visual observation of the simulant surface in the feed tank (no bubbles present) confirmed that air was purged from the system.

Next, the data logger was set up for testing, the test header (with all the required OTPs in place) was securely installed, and a pretest checklist of system configuration checks was completed. This checklist included agitating and recirculating the simulant for at least 5 minutes, during which time the simulant density (measured by the Coriolis meter in the test header) was recorded every 30 seconds. The simulant temperature in the test header was recorded at the beginning and end of the 5-minute period. If the measured densities were within a specified tolerance of the target density, chosen to indicate that the solids concentration was within $10 \%$ of the target value, the test proceeded and two pre-test samples were taken from the top of the feed tank. 
After the target pressure and flow rate in the bypass header were adjusted (manually) to within $10 \%$ and $20 \%$ of their target values, respectively, the test header was opened to allow flow through the OTP leak orifices. However, normally the pressure and flow rate were set very close to the target values and the listed tolerance was used to account for system drift, providing time for the operator to adjust the values back to as close as reasonably achievable. The flow and pressure were re-adjusted to target values; when the targets were reached, the time, flow rate, and pressure were recorded. The sprays were photographed for documentation purposes at approximately time zero, 15 minutes, and (optionally) at other times during the test. When 15 minutes had passed and the test was complete, two post-test samples were taken from the feed tank, flow was sent through the bypass, the pump was shut off, the data logger file was saved, and the simulant that had collected in the enclosure was reused (i.e., pumped back into the feed tank).

If a different type of simulant was planned for the next test, a cleaning and flushing procedure was followed. The simulant was mixed with the agitator while the tank was being drained, with the agitator being shut off when the simulant level reached the agitator blades. A diaphragm pump was attached and tap water was used to rinse and flush the system. After that, one or two water spray tests were conducted, with the smallest set of orifices in place, to further flush the system and confirm that no particles or debris were present that could cause false plugging.

\subsection{Examination of Test Orifices}

The optical examinations of test orifices that were performed to support plugging tests served several purposes:

1. a pre-test confirmation that all orifices to be tested were clean and clear before beginning a test;

2. a post-test determination of whether any observed plugging was caused by simulant particles or by debris in the system;

3. a comparison of size measurements made before and after the plugging test series to check whether the orifices had changed measurably because of abrasion or permanent blockage caused by the tests.

Both back-lit and front-lit images were captured to ensure that the condition of the orifices was completely observed.

When plugging was found to have been caused by debris rather than by simulant particles, the test was re-run at the same conditions until post-test observations showed no debris in the orifices. The debris that was observed was distinctive in appearance, including strands of Teflon sealing tape or brush bristle. 


\subsection{Plugging Test Results}

In order to conservatively support an assumption that a leak becomes plugged and spray release is prevented, the test results must show that a given size of orifice consistently plugs with typical concentrations of solids with a PSD that represents the smaller expected size distributions of waste. The evidence related to this point is discussed below.

Particle size distributions were measured on samples taken before and after the plugging tests to assess whether changes had occurred due to particle settling or size reduction (Table 6.1). The simulant identifiers in the first column are defined in Chapter 3 and summarized in Table 5.3: the "-8" and "-20" indicate the target solids loading, $8 \mathrm{wt} \%$ or $20 \mathrm{wt} \%$ UDS. The PSDs for the SAR- 8 simulant show little change. The generally smaller PSDs observed for the TAR- 8 simulant after testing indicate some size reduction, agglomerate breakup or settling loss of the largest particles. The observations of much larger particles in the post-testing STR-8 simulant may have resulted either from agglomeration or from air bubbles introduced to the instrument.

Table 6.1. Effect of Testing on Simulant PSD

\begin{tabular}{|c|c|c|c|c|c|c|c|c|c|c|}
\hline \multirow{3}{*}{ Simulant } & \multicolumn{10}{|c|}{ Particle Sizes $(\mu \mathrm{m})$ by Volume Percentile } \\
\hline & \multicolumn{5}{|c|}{ Before First Run with Batch } & \multicolumn{5}{|c|}{ After Last Run with Batch } \\
\hline & $10^{\text {th }}$ & $50^{\text {th }}$ & $90^{\text {th }}$ & $99^{\text {th }}$ & $100^{\text {th }}$ & $10^{\text {th }}$ & $50^{\text {th }}$ & $90^{\text {th }}$ & $99^{\text {th }}$ & $100^{\text {th }}$ \\
\hline SAR-8 & 1.2 & 3.0 & 14 & 27 & 40 & 1.1 & 2.8 & 15 & 28 & 40 \\
\hline SAR-20 & 1.2 & 2.8 & 13 & 26 & 40 & $\mathrm{n} / \mathrm{m}$ & $\mathrm{n} / \mathrm{m}$ & $\mathrm{n} / \mathrm{m}$ & $\mathrm{n} / \mathrm{m}$ & $\mathrm{n} / \mathrm{m}$ \\
\hline TAR-8 & 1.7 & 8.4 & 25 & 43 & 56 & 1.5 & 6.1 & 18 & 31 & 40 \\
\hline TAR-20 & 1.8 & 8.8 & 26 & 43 & 56 & $\mathrm{n} / \mathrm{m}$ & $\mathrm{n} / \mathrm{m}$ & $\mathrm{n} / \mathrm{m}$ & $\mathrm{n} / \mathrm{m}$ & $\mathrm{n} / \mathrm{m}$ \\
\hline STR-8 & 0.48 & 0.98 & 2.2 & 8.8 & 20 & 0.48 & 1.0 & 31 & 155 & 283 \\
\hline STR-20 & 0.45 & 0.91 & 2.0 & 10.0 & 20 & $\mathrm{n} / \mathrm{m}$ & $\mathrm{n} / \mathrm{m}$ & $\mathrm{n} / \mathrm{m}$ & $\mathrm{n} / \mathrm{m}$ & $\mathrm{n} / \mathrm{m}$ \\
\hline
\end{tabular}

The main results of the plugging tests are shown in Table 6.2. Except for one case, the tests were conducted with the fluid flowing past the orifice as indicated by "axial" in the third column. In one test, the line was blocked and the test was conducted in a dead-end configuration. Each test was conducted for $15 \mathrm{~min}$, and the plugging time was noted by visual observation of the spray for the orifices that plugged.

No combination of simulant and pressure produced plugging for round orifices with an outer diameter $\geq 382 \mu \mathrm{m}$ or for slots with a smallest outer dimension (width) $\geq 260 \mu \mathrm{m}$. The smallest round orifice tested had a diameter of $0.188 \mathrm{~mm}$ at the inside of the OTP; it plugged in 9 of the 11 tests. All of the tests at $20 \mathrm{wt} \%$ UDS plugged the smallest orifice.

The ratio of the orifice inner diameter to the $100^{\text {th }}$ percentile particle size was $3-5$ for the SAR and TAR simulants both before and after testing. The literature summarized in Section 1.1 indicated that, depending on conditions, orifice/particle ratios of $2-5$ could allow plugging by monodisperse particles, although some degree of cohesiveness might be needed for plugging to occur at ratios of 3 and greater.

The orifice/particle ratio, for the $100^{\text {th }}$ percentile STR particle, was $\sim 9$ for the pre-test STR simulant and $<1$ for the post-test STR simulant. Since the STR simulant usually produced plugging, it seems likely 
that at least some of the larger solids that appeared in the post-test simulant were aggregates that were also present during the test. For this simulant, cohesiveness was probably a major factor in plugging.

One of the tests in which the smallest orifice was not plugged used a simulant that represented the smallest PSD (STR) with a solids concentration of $8 \mathrm{wt} \%$ UDS $(2.8 \mathrm{vol} \%$ solid $) .{ }^{1}$ For this simulant, the maximum measured particle size, $20 \mu \mathrm{m}$, was larger than the maximum target particle size, $8 \mu \mathrm{m}$. The target PSDs were based on measurements obtained on an actual waste sample that had been washed and leached. The target STR simulant might be less likely to cause plugging than the actual STR simulant, based on particle size alone. However, since cohesion played a part in plugging with STR, it is not clear that decreased particle size would offset the cohesiveness and reduce the chances of plugging.

The other test that did not plug the smallest orifice used a simulant that represented a TAR waste with a solids concentration of $8 \mathrm{wt} \%$ (3.5 vol\% solid). The maximum measured particle size, $56 \mu \mathrm{m}$, was smaller than the maximum target particle size, $792 \mu \mathrm{m}$. In this case the target simulant would contain particles whose orifice/particle ratio would be $<1$ for the smallest orifice tested, as well as for several larger OTPs. Plugging would be nearly unavoidable for ratios $<1$.

The test results indicate that orifice plugging may be a function of solids concentration, but there is no observable plugging trend as a function of simulant particle size over the size range tested. Given that some of the actual wastes have particles larger than the maximum particle size of the simulants, it is likely that some, but not all, actual wastes could consistently plug the orifices tested.

There was no clear trend to demonstrate an effect of pressure (flow velocity) on plugging. There was also no information to determine whether a slot of a given width would plug as easily as a round orifice of the same width.

\footnotetext{
${ }^{1}$ The volume concentrations were calculated using densities of $3.01 \mathrm{~g} / \mathrm{cc}$ for boehmite, $2.42 \mathrm{~g} / \mathrm{cc}$ for gibbsite, and $0.998 \mathrm{~g} / \mathrm{cc}$ for water.
} 
Table 6.2. Results of Plugging Tests

\begin{tabular}{|c|c|c|c|c|c|c|c|c|}
\hline \multirow[b]{2}{*}{ Simulant } & \multirow{2}{*}{$\begin{array}{c}\text { Nominal } \\
\text { Pressure } \\
\text { (psig) }\end{array}$} & \multirow[b]{2}{*}{$\begin{array}{c}\text { Flow } \\
\text { Orientation }\end{array}$} & \multicolumn{4}{|c|}{ Circular (time to plug, min:sec) } & \multicolumn{2}{|c|}{ Slot $^{(b)}$} \\
\hline & & & $\begin{array}{c}0.245 \mathrm{~mm}^{(a)} \\
0.188 \mathrm{~mm}^{\text {a) }}\end{array}$ & $\begin{array}{c}0.382 \\
\mathrm{~mm}\end{array}$ & $\begin{array}{c}0.534 \\
\mathrm{~mm}\end{array}$ & $\begin{array}{c}0.706 \\
\mathrm{~mm}\end{array}$ & $\begin{array}{c}0.260 \mathrm{x} \\
4.946 \mathrm{~mm}\end{array}$ & $\begin{array}{c}0.357 \mathrm{x} \\
5.021 \mathrm{~mm}\end{array}$ \\
\hline STR-8 & 100 & axial & - & - & - & - & - & NT \\
\hline STR-8 & 200 & axial & $\mathrm{P}(1: 55)$ & - & - & - & - & NT \\
\hline STR-8 & 380 & axial & $\mathrm{P}(5: 32)$ & - & - & - & - & NT \\
\hline STR-8 & 380 & dead-end & $\mathrm{P}(0: 15)$ & - & NT & NT & NT & NT \\
\hline STR-20 & 380 & axial & $\mathrm{P}(9: 20)$ & - & - & - & - & - \\
\hline SAR-8 & 100 & axial & $\mathrm{P}(6: 15)$ & - & - & - & NT & NT \\
\hline SAR-8 & 380 & axial & $\mathrm{P}(2: 39)$ & - & - & - & NT & NT \\
\hline SAR-20 & 200 & axial & $\mathrm{P}(13: 55)$ & - & - & - & NT & NT \\
\hline SAR-20 & 380 & axial & $\mathrm{P}(1: 32)$ & - & - & - & NT & NT \\
\hline TAR-8 & 380 & axial & - & - & - & - & - & - \\
\hline TAR-20 & 380 & axial & $\mathrm{P}(1: 29)$ & - & - & - & - & - \\
\hline $\begin{array}{l}\text { (a) } \begin{array}{r}\text { The d } \\
\text { diverg } \\
\text { given. } \\
\text { subse }\end{array} \\
\text { "P" = spra } \\
\text { "_" = test } \\
\text { "NT" = no } \\
\text { (b) The OT }\end{array}$ & $\begin{array}{l}\text { he inner di } \\
\text { nt aerosol } \\
\text { opped by } \\
\text { wed no pl } \\
\text { sted. } \\
\text { slot orifice }\end{array}$ & $\begin{array}{l}\text { rifice was } 0.2 \\
\text { age. The oth } \\
\text { leter could no } \\
\text { ting. } \\
\text { gging with si } \\
\text { ging. } \\
\text { vere oriented }\end{array}$ & $\begin{array}{l}\mathrm{mm} \text { at the ou } \\
\text { orifices were } \\
\text { be measured } \mathrm{x} \\
\text { ulant. }\end{array}$ & $\begin{array}{l}\text { end of } \\
\text { diver } \\
\text { out des }\end{array}$ & $\begin{array}{l}\text { hole a } \\
\text { to sol } \\
\text { ing the }\end{array}$ & $\begin{array}{l}0.188 \\
\text { extent } \\
\text { TPs, v }\end{array}$ & $\begin{array}{l}\text { at the inne } \\
\text { eir outer dir } \\
\text { h were nee }\end{array}$ & $\begin{array}{l}\text { d, giving a } \\
\text { sions are } \\
\text { for }\end{array}$ \\
\hline
\end{tabular}





\subsection{Conclusions}

The study provided experimental data for plugging of small breaches by testing a range of orifice sizes and orientations representative of the WTP conditions. The simulants used were chosen to represent the range of process stream properties in the WTP; they were $8 \mathrm{wt} \%$ and $20 \mathrm{wt} \%$ slurries of boehmite/water and gibbsite/water. The PSDs of the simulant slurries included a range of sizes from $\mathrm{d}_{50}=0.98-8.4 \mu \mathrm{m}, \mathrm{d}_{99}=8.8-43 \mu \mathrm{m}$, and $\mathrm{d}_{100}$ (maximum measured particle size at the start of testing $=20-56 \mu \mathrm{m}$. In general, these slurry simulants were Newtonian or weakly non-Newtonian; the highest Bingham yield stress measured was 1.5 Pa.

The main results of the plugging tests are shown in Table 7.1 (which is a duplicate of Table 6.2).

Table 7.1. Results of Plugging Tests

\begin{tabular}{|c|c|c|c|c|c|c|c|c|}
\hline \multirow[b]{2}{*}{ Simulant } & \multirow{2}{*}{$\begin{array}{c}\text { Nominal } \\
\text { Pressure } \\
\text { (psig) }\end{array}$} & \multirow[b]{2}{*}{$\begin{array}{c}\text { Flow } \\
\text { Orientation }\end{array}$} & \multicolumn{4}{|c|}{ Circular (time to plug, min:sec) } & \multicolumn{2}{|c|}{ Slot $^{(b)}$} \\
\hline & & & $\begin{array}{c}0.245 \mathrm{~mm}^{\text {(a) }} \\
0.188 \mathrm{~mm}^{2}\end{array}$ & $\begin{array}{c}0.382 \\
\mathrm{~mm}\end{array}$ & $\begin{array}{c}0.534 \\
\mathrm{~mm}\end{array}$ & $\begin{array}{c}0.706 \\
\mathrm{~mm}\end{array}$ & $\begin{array}{c}0.260 \mathrm{x} \\
4.946 \mathrm{~mm} \\
\end{array}$ & $\begin{array}{c}0.357 \mathrm{x} \\
5.021 \mathrm{~mm} \\
\end{array}$ \\
\hline STR-8 & 100 & axial & - & - & - & - & - & NT \\
\hline STR-8 & 200 & axial & $\mathrm{P}(1: 55)$ & - & - & - & - & NT \\
\hline STR-8 & 380 & axial & $\mathrm{P}(5: 32)$ & - & - & - & - & NT \\
\hline STR-8 & 380 & dead-end & $\mathrm{P}(0: 15)$ & - & NT & NT & NT & NT \\
\hline STR-20 & 380 & axial & $\mathrm{P}(9: 20)$ & - & - & - & - & - \\
\hline SAR-8 & 100 & axial & $\mathrm{P}(6: 15)$ & - & - & - & NT & NT \\
\hline SAR-8 & 380 & axial & $\mathrm{P}(2: 39)$ & - & - & - & NT & NT \\
\hline SAR-20 & 200 & axial & $\mathrm{P}(13: 55)$ & - & - & - & NT & NT \\
\hline SAR-20 & 380 & axial & $\mathrm{P}(1: 32)$ & - & - & - & NT & NT \\
\hline TAR-8 & 380 & axial & - & - & - & - & - & - \\
\hline TAR-20 & 380 & axial & $\mathrm{P}(1: 29)$ & - & - & - & - & - \\
\hline \multicolumn{9}{|c|}{$\begin{array}{l}\text { (a) The diameter of this orifice was } 0.245 \mathrm{~mm} \text { at the outer end of the hole and } 0.188 \mathrm{~mm} \text { at the inner } \\
\text { diverging conical passage. The other orifices were also divergent, to some extent; their outer dim } \\
\text { given. The inner diameter could not be measured without destroying the OTPs, which were need } \\
\text { subsequent aerosol testing. } \\
\text { (b) The OTP slot orifices were oriented longitudinally, with the slot length along the flow direction. } \\
\text { "P" = spray stopped by plugging with simulant. } \\
\text { "-" = test showed no plugging. } \\
\text { "NT"= not tested. }\end{array}$} \\
\hline
\end{tabular}

In general, no consistent distinction could be made between the simulants in terms of plugging behavior, nor was there any recognizable trend with particle size or cohesiveness. There was also no clear trend to demonstrate an effect of pressure (flow velocity) on plugging.

No combination of simulant and pressure produced plugging for round orifices with an outer diameter $\geq 382 \mu \mathrm{m}$ or for slots with a smallest outer dimension (width) $\geq 260 \mu \mathrm{m}$. The smallest round orifice tested had a diameter of $0.188 \mathrm{~mm}$ at the inside of the OTP; it plugged in 9 of the 11 tests. All of the tests at $20 \mathrm{wt} \%$ UDS plugged the smallest orifice. The orifice dimensions that can be assumed to consistently plug are smaller than the orifice dimensions tested with the range of simulants and pressures indicated in Table 7.1. 



\subsection{References}

Campbell T, M Parker, A Moon, B Fant, K Clossey, and J Cook. 2010. EFRT Issue M3 PJM Vessel Mixing Assessment, Volume 8 - HLP-22. 24590-WTP-RPT-ENG-08-021-08, Rev. 1, River Protection Project, Waste Treatment Plant, Richland, Washington.

Epstein M and MG Plys. 2006. Measured Drop Size Distributions Within Cold Sprays Emanating from Small Leak Openings. FAI/06-55, Fauske \& Associates LLC, Burr Ridge Illinois.

Herzig JP, DM Leclerc, and P Le Goff. 1970. "Flow of Suspensions Through Porous Media - Application to Deep Filtration." Ind. Eng. Chem. 62(5):8-35.

Hey BE and DS Leach. 1994. A Model for Predicting Respirable Releases from Pressurized Leaks. WHC-SD-GN-SWD-20007 Rev. 0, Westinghouse Hanford Company, Richland, Washington.

Hirochi T, S Yamada, T Shintate, and M Shirakashi. 2002. "Ice/Water Slurry Blocking Phenomenon at a Tube Orifice." Ann. N.Y. Acad. Sci. 972:171-176.

HNF-SD-WM-SAR-062, Revision 10D, K Basins Final Safety Analysis Report.

ICD 19. 2011. ICD 19 - Interface Control Document for Waste Feed. 24590-WTP-ICD-MG-01-19, Rev 5, River Protection Project, Waste Treatment Plant, Richland, Washington.

Kurath DE, BD Hanson, MJ Minette, DL Baldwin, BM Rapko, LA Mahoney, PP Schonewill, RC Daniel, PW Eslinger, JL Huckaby, JM Billing, PS Sundar, GB Josephson, JJ Toth, ST Yokuda, EBK Baer, SM Barnes, EC Golovich, SD Rassat, CF Brown, JGH Geeting, GJ Sevigny, AJ Casella, JR Bontha, RL Aaberg, PM Aker, CE Guzman-Leong, ML Kimura, SK Sundaram, RP Pires, BE Wells, and OP Bredt. 2009. Pretreatment Engineering Platform Phase I Final Test Report. PNNL-18894, WTP-RPT-197, Pacific Northwest National Laboratory, Richland, Washington.

Larson AR and BT Allen. 2010. WTP Methodology for Spray Leak Scenarios.

24590-WTP-RPT-ENS-10-001, Rev. 1, River Protection Project, Waste Treatment Plant, Richland, Washington.

Mahoney LA, PA Gauglitz, ML Kimura, GN Brown, DE Kurath, J Blanchard, C Song, RC Daniel, BE Wells, and D Tran. 2012. Small-Scale Spray Releases: Aerosol Test Results. WTP-RPT-216 Rev A (to be published), Pacific Northwest National Laboratory, Richland, Washington.

Pandya VB, S Bhuniya, and KC Khilar. 1998. "Existence of a Critical Particle Concentration in Plugging of a Packed Bed." AIChE J 44(4):978-981.

Schonewill PP, PA Gauglitz, JR Bontha, RD Daniel, JJ Jenks, DE Kurath, JM Billing, HE Adkins, Jr., CW Enderlin, CA Burns, C Fischer, CD Lukins, JL Shutthanandan, and DM Smith. 2012. Large-Scale Spray Releases: Aerosol Test Results. WTP-RPT-217 Rev A (to be published), Pacific Northwest National Laboratory, Richland, Washington. 
Wells BE, DE Kurath, LA Mahoney, Y Onishi, JL Huckaby, SK Cooley, CA Burns, EC Buck, JM Tingey, RC Daniel, and KK Anderson. 2011. Hanford Waste Physical and Rheological Properties: Data and Gaps. PNNL-20646, EMSP-RPT-006, Pacific Northwest National Laboratory, Richland, Washington.

Zimmerman BD. 2003. Waste Transfer Leaks Technical Basis Document. RPP-13750, Rev. 0, CH2MHILL Hanford Group, Inc., Richland, Washington.

Zuriguel I, A Garcimartín, D Maza, LA Pugnaloni, and JM Pastor. 2005. "Jamming during the discharge of granular matter from a silo." Phys. Rev. E 71:051303-1-9. 
Appendix A

\section{List of Test Documents}





\section{Appendix A}

\section{List of Test Documents}

The test documents that define or describe the plugging tests are listed below:

Gauglitz PA. 2011. Test Plan for Spray Leak Quantification to Support WTP Spray Release Methodology, TP-WTPSP-031 R0.1.

Appendix A of the test plan describes the basis for simulant development.

Kimura ML. 2011. Spray Release Methodology Small-Scale Plugging Tests Project Plan, PP-WTPSP-033 Rev 1.

Test Instructions TI-WTPSP-036 (“Test Instruction and Procedure for Small Scale Plugging Tests"), TI-WTPSP-036 ("Simulant Blending to Support Small-Scale Spray Testing”), and TI-WTPSP-041 (“Test Instruction and Procedure for Small Scale Plugging Tests").

Laboratory Record Book BNW-61117, pages 1-56.

TDP-WTPSP-611 (initial water shakedown).

TDP-WTPSP-613 through -615 (SS-P-PV3 tests).

TDP-WTPSP-616 through -618 (SS-P-PV1 tests).

TDP-WTPSP-619 (SS-P-S7-380 test).

TDP-WTPSP-620 (SS-P-S9-380 test).

TDP-WTPSP-621 (water cleanout tests between STR-20 and TAR-8 simulants).

TDP-WTPSP-622 (SS-P-S25-380 test).

TDP-WTPSP-623 (SS-P-S27-380 test).

TDP-WTPSP-624 (SS-P-S31-380 test).

TDP-WTPSP-625 (SS-P-S33-380 test).

TDP-WTPSP-626 (water cleanout tests between TAR-20 and SAR-20 simulants).

TDP-WTPSP-627 (SS-P-S19-380, SS-P-S19-380-R1, SS-P-S19-380-R2 tests, repeated because of debris plugging).

TDP-WTPSP-628 (SS-P-S19-200 test). 
TDP-WTPSP-629 (water cleanout tests between SAR-20 and STR-8 simulants).

TDP-WTPSP-630, -631 (SS-P-SO48-380 tests).

TDP-WTPSP-632 (water cleanout tests between STR-8 and SAR-8 simulants).

TDP-WTPSP-633, -634 (SS-P-S13 tests).

TDP-WTPSP-502 (PSD data for samples from all simulant tests).

TDP-WTPSP-503 (rheological data for samples from all simulant tests).

CCP-WTPSP-1145 Rev 1, "Small-Scale Plugging-Tests Wall Shear Stress.” Originator LA Mahoney.

CCP-WTPSP-1148, “Summary of Plugging Test Results.” Originator J Blanchard.

CCP-WTPSP-1158, “PSDs for Spray Leak Project Simulant.” Originator BE Wells.

CCP-WTPSP-1159, "Image Analysis of OTP for Small Scale Spray Release Plugging Tests." Originator PP Schonewill.

CCP-WTPSP-1160, "PSD Plots for Simulants.” Originator LA Mahoney. 
Appendix B

\section{Cross-Reference for Tests}





\section{Appendix B}

\section{Cross-Reference for Tests}

The tables in this appendix provide a more detailed summary of the test conditions, results, and observations than was presented in the overview in Table 6.2. These tables also include cross-references to the test instructions, test data packages, and LRB pages in which further information can be found.

In Table B.1, tests are listed in the order in which they were performed. The simulants are identified as in Chapter 3 with the simulant aliases identified in Table 5.3. The test naming convention for the plugging tests was SS-P-@\#-\#\#\#, where SS-P indicates small-scale plugging, -@ indicates the objective of the individual test (i.e., $\mathrm{PV}=$ pressure variation, $\mathrm{S}=$ simulant evaluation, $\mathrm{SO}=$ slot orifice size variation, etc.), \# indicates the overall plugging test number from 1 to $\mathrm{N}$ (where $\mathrm{N}$ is the sequential test number), and \#\#\# indicates the test pressure. In some cases an R\# is appended to the test name. This indicates that a retest was conducted and the number indicates the sequential retest number. Water runs were made before starting each new simulant to help purge the system and check for debris. The naming convention for the water tests did not follow a specified convention. Plugging is indicated by a "Y" in the "Plug (Y/N)" column for each orifice. Blank entries for orifices indicate that less than four OTPs were used during the run. In some tests with high flow rates, it was necessary to recycle simulant from the test enclosure to the feed tank in mid-run, which is indicated by a "Y" in the "Recycle (Y/N)" column.

Table B.2 shows how many PSD and rheological tests were run on pre-test and post-test samples for each test. The table also gives some details of plugging observations, including cases in which debris was observed. More information can be found in the test instructions identified by the "TI \#" column, the technical data packages identified in the "TDP \#" column, and the laboratory record book pages stated in the "LRB Page \#" column. 
Table B.1. Test Conditions

\begin{tabular}{|c|c|c|c|c|c|c|c|c|c|c|c|}
\hline \multirow[b]{2}{*}{ Test ID } & \multirow[b]{2}{*}{ Simulant } & \multicolumn{2}{|c|}{ Orifice 1} & \multicolumn{2}{|c|}{ Orifice 2} & \multicolumn{2}{|c|}{ Orifice 3} & \multicolumn{2}{|c|}{ Orifice 4} & \multirow[b]{2}{*}{$\begin{array}{c}\text { Nominal } \\
\text { Pressure } \\
\text { (psig) }\end{array}$} & \multirow[b]{2}{*}{$\begin{array}{c}\text { Recycle }^{(\mathrm{a})} \\
(\mathrm{Y} / \mathrm{N})\end{array}$} \\
\hline & & $\begin{array}{l}\text { Outer Size } \\
\quad(\mathrm{mm})\end{array}$ & $\begin{array}{l}\text { Plug } \\
(\mathrm{Y} / \mathrm{N})\end{array}$ & $\begin{array}{l}\text { Outer } \\
\text { Size } \\
(\mathrm{mm})\end{array}$ & $\begin{array}{l}\text { Plug } \\
(\mathrm{Y} / \mathrm{N})\end{array}$ & $\begin{array}{l}\text { Outer } \\
\text { Size } \\
(\mathrm{mm})\end{array}$ & $\begin{array}{c}\text { Plug } \\
(\mathrm{Y} / \mathrm{N})\end{array}$ & $\begin{array}{l}\text { Outer } \\
\text { Size } \\
(\mathrm{mm})\end{array}$ & $\begin{array}{l}\text { Plug } \\
(\mathrm{Y} / \mathrm{N})\end{array}$ & & \\
\hline SS-P-Water1-380 & Tap Water & 0.245 & $\mathrm{Y}$ & 0.382 & $\mathrm{~N}$ & 0.534 & $\mathrm{~N}$ & 0.706 & $\mathrm{~N}$ & 380 & $\mathrm{~N}$ \\
\hline SS-P-Water1-200 & Tap Water & 0.245 & $\mathrm{~N}$ & 0.382 & $\mathrm{~N}$ & 0.534 & $\mathrm{~N}$ & 0.706 & $\mathrm{~N}$ & 200 & $\mathrm{~N}$ \\
\hline SS-P-Water1-100 & Tap Water & 0.245 & $\mathrm{~N}$ & 0.382 & $\mathrm{~N}$ & 0.534 & $\mathrm{~N}$ & 0.706 & $\mathrm{~N}$ & 100 & $\mathrm{~N}$ \\
\hline SS-P-Water1B-380 & Tap Water & 0.245 & $\mathrm{~N}$ & 0.382 & $\mathrm{~N}$ & 0.534 & $\mathrm{~N}$ & 0.706 & $\mathrm{~N}$ & 380 & $\mathrm{~N}$ \\
\hline SS-P-PV3-380 & $8 \mathrm{wt} \% \mathrm{STR}$ & - & - & $\begin{array}{c}0.260 \times \\
0.4946\end{array}$ & $\mathrm{~N}$ & - & - & - & - & 380 & $\mathrm{~N}$ \\
\hline SS-P-PV3-200 & $8 \mathrm{wt} \% \mathrm{STR}$ & - & - & $\begin{array}{c}0.260 \times \\
0.4946\end{array}$ & $\mathrm{~N}$ & - & - & - & - & 200 & $\mathrm{~N}$ \\
\hline SS-P-PV3-100 & $8 \mathrm{wt} \% \mathrm{STR}$ & - & - & - & - & $\begin{array}{c}0.260 \times \\
0.4946\end{array}$ & $\mathrm{~N}$ & - & - & 100 & $\mathrm{~N}$ \\
\hline SS-P-PV1-380 & $8 \mathrm{wt} \% \mathrm{STR}$ & 0.245 & $\mathrm{Y}$ & 0.382 & $\mathrm{~N}$ & 0.534 & $\mathrm{~N}$ & 0.706 & $\mathrm{~N}$ & 380 & $\mathrm{~N}$ \\
\hline SS-P-PV1-200 & $8 \mathrm{wt} \% \mathrm{STR}$ & 0.245 & $\mathrm{Y}$ & 0.382 & $\mathrm{~N}$ & 0.534 & $\mathrm{~N}$ & 0.706 & $\mathrm{~N}$ & 200 & $\mathrm{~N}$ \\
\hline SS-P-PV1-100 & $8 \mathrm{wt} \% \mathrm{STR}$ & 0.245 & $\mathrm{~N}$ & 0.382 & $\mathrm{~N}$ & 0.534 & $\mathrm{~N}$ & 0.706 & $\mathrm{~N}$ & 100 & $\mathrm{~N}$ \\
\hline SS-P-S7-380 & $20 \mathrm{wt} \% \mathrm{STR}$ & 0.245 & $\mathrm{Y}$ & 0.382 & $\mathrm{~N}$ & 0.534 & $\mathrm{~N}$ & 0.706 & $\mathrm{~N}$ & 380 & $\mathrm{~N}$ \\
\hline SS-P-S9-380 & $20 \mathrm{wt} \% \mathrm{STR}$ & $\begin{array}{c}0.260 \times \\
0.4946\end{array}$ & $\mathrm{~N}$ & $\begin{array}{c}0.357 \times \\
0.5021\end{array}$ & $\mathrm{~N}$ & - & - & - & - & 380 & $\mathrm{Y}$ \\
\hline SS-P-TAR8-H2O3 & Tap Water & 0.222 & Y & 0.382 & $\mathrm{~N}$ & 0.534 & $\mathrm{~N}$ & 0.706 & $\mathrm{~N}$ & 380 & $\mathrm{~N}$ \\
\hline SS-P-TAR8-H2O3B & Tap Water & 0.222 & $\mathrm{~N}$ & 0.382 & $\mathrm{~N}$ & 0.534 & $\mathrm{~N}$ & 0.706 & $\mathrm{~N}$ & 380 & $\mathrm{~N}$ \\
\hline SS-P-S25-380 & $8 \mathrm{wt} \%$ TAR & 0.382 & $\mathrm{~N}$ & 0.534 & $\mathrm{~N}$ & 0.706 & $\mathrm{~N}$ & 0.245 & $\mathrm{~N}$ & 380 & $\mathrm{~N}$ \\
\hline SS-P-S27-380 & $8 w t \%$ TAR & - & - & - & - & $\begin{array}{c}0.260 \times \\
0.4946\end{array}$ & $\mathrm{~N}$ & $\begin{array}{c}0.357 x \\
0.5021\end{array}$ & $\mathrm{~N}$ & 380 & $\mathrm{Y}$ \\
\hline SS-P-S31-380 & $20 \mathrm{wt} \% \mathrm{TAR}$ & 0.245 & $\mathrm{Y}$ & 0.382 & $\mathrm{~N}$ & 0.534 & $\mathrm{~N}$ & 0.706 & $\mathrm{~N}$ & 380 & $\mathrm{~N}$ \\
\hline SS-P-S33-380 & $20 \mathrm{wt} \% \mathrm{TAR}$ & - & - & - & - & $\begin{array}{c}0.260 \times \\
0.4946\end{array}$ & $\mathrm{~N}$ & $\begin{array}{c}0.357 x \\
0.5021\end{array}$ & $\mathrm{~N}$ & 380 & $\mathrm{Y}$ \\
\hline SS-P-SAR20-H2O2 & Tap Water & 0.245 & $\mathrm{~N}$ & 0.382 & $\mathrm{~N}$ & 0.534 & $\mathrm{~N}$ & 0.706 & $\mathrm{~N}$ & 380 & $\mathrm{~N}$ \\
\hline SS-P-S19-380 & $20 \mathrm{wt} \% \mathrm{SAR}$ & 0.245 & $\mathrm{Y}$ & 0.382 & $\mathrm{Y}$ & 0.534 & $\mathrm{Y}$ & 0.706 & $\mathrm{~N}$ & 380 & $\mathrm{~N}$ \\
\hline SS-P-S19-380-R1 & $20 \mathrm{wt} \% \mathrm{SAR}$ & 0.245 & $\mathrm{Y}$ & 0.382 & $\mathrm{~N}$ & 0.534 & $\mathrm{~N}$ & 0.706 & $\mathrm{~N}$ & 380 & $\mathrm{~N}$ \\
\hline SS-P-S19-380-R2 & $20 \mathrm{wt} \% \mathrm{SAR}$ & 0.245 & $\mathrm{Y}$ & 0.382 & $\mathrm{~N}$ & 0.534 & $\mathrm{~N}$ & 0.706 & $\mathrm{~N}$ & 380 & $\mathrm{~N}$ \\
\hline
\end{tabular}


Table B.1. (contd)

\begin{tabular}{|c|c|c|c|c|c|c|c|c|c|c|c|}
\hline \multirow[b]{2}{*}{ Test ID } & \multirow[b]{2}{*}{ Simulant } & \multicolumn{2}{|c|}{ Orifice 1} & \multicolumn{2}{|c|}{ Orifice 2} & \multicolumn{2}{|c|}{ Orifice 3} & \multicolumn{2}{|c|}{ Orifice 4} & \multirow{2}{*}{$\begin{array}{l}\text { Nominal } \\
\text { Pressure } \\
\text { (psig) }\end{array}$} & \multirow[b]{2}{*}{$\begin{array}{c}\text { Recycle }^{(\mathrm{a})} \\
(\mathrm{Y} / \mathrm{N})\end{array}$} \\
\hline & & Size $(\mathrm{mm})$ & $\begin{array}{c}\text { Plug } \\
(\mathrm{Y} / \mathrm{N})\end{array}$ & $\begin{array}{l}\text { Size } \\
(\mathrm{mm})\end{array}$ & $\begin{array}{l}\text { Plug } \\
(\mathrm{Y} / \mathrm{N})\end{array}$ & $\begin{array}{c}\text { Size } \\
(\mathrm{mm})\end{array}$ & $\begin{array}{l}\text { Plug } \\
(\mathrm{Y} / \mathrm{N})\end{array}$ & $\begin{array}{l}\text { Size } \\
(\mathrm{mm})\end{array}$ & $\begin{array}{c}\text { Plug } \\
(\mathrm{Y} / \mathrm{N})\end{array}$ & & \\
\hline SS-P-S19-200 & $20 \mathrm{wt} \% \mathrm{SAR}$ & 0.245 & $\mathrm{Y}$ & 0.382 & $\mathrm{~N}$ & 0.534 & $\mathrm{~N}$ & 0.706 & $\mathrm{~N}$ & 200 & $\mathrm{~N}$ \\
\hline SS-P-STR8-H2O8 & Tap Water & 0.245 & $\mathrm{~N}$ & 0.382 & $\mathrm{~N}$ & 0.534 & $\mathrm{~N}$ & 0.706 & $\mathrm{~N}$ & 380 & $\mathrm{~N}$ \\
\hline SS-P-SO48-380 & $8 \mathrm{wt} \% \mathrm{STR}$ & 0.245 & $\mathrm{Y}$ & - & - & - & - & - & - & 380 & $\mathrm{~N}$ \\
\hline SS-P-SO48-380-300 & $8 \mathrm{wt} \% \mathrm{STR}$ & 0.382 & $\mathrm{~N}$ & - & - & - & - & - & - & 380 & $\mathrm{~N}$ \\
\hline SS-P-SAR8-H2O1 & Tap Water & 0.245 & $\mathrm{~N}$ & 0.382 & $\mathrm{~N}$ & 0.534 & $\mathrm{~N}$ & 0.706 & $\mathrm{~N}$ & 380 & $\mathrm{~N}$ \\
\hline SS-P-S13-380 & $8 w t \%$ SAR & 0.245 & $\mathrm{Y}$ & 0.382 & $\mathrm{~N}$ & 0.534 & $\mathrm{~N}$ & 0.706 & $\mathrm{~N}$ & 380 & $\mathrm{~N}$ \\
\hline SS-P-S13-100 & $8 \mathrm{wt} \% \mathrm{SAR}$ & 0.245 & $\mathrm{Y}$ & 0.382 & $\mathrm{~N}$ & 0.534 & $\mathrm{~N}$ & 0.706 & $\mathrm{~N}$ & 100 & $\mathrm{~N}$ \\
\hline
\end{tabular}

(a) Recycle is defined as a transfer of simulant from the enclosure back into the feed tank during a test. Recycle was infrequent. The more frequent transfers from enclosure to feed tank that occurred between tests were called "re-use." 
Table B.2. Test Observations and Records

\begin{tabular}{|c|c|c|c|c|c|c|}
\hline Test ID & PSD (Pre/Post) & $\begin{array}{l}\text { Rheology } \\
\text { (Pre/Post) }\end{array}$ & Observations & TI \# & TDP \# & $\begin{array}{c}\text { LRB } \\
\text { Page \# }\end{array}$ \\
\hline SS-P-Water1-380 & - & - & $245 \mathrm{~mm}$ plugged by brush bristle. & 036 & 611 & 13 \\
\hline SS-P-Water1-200 & - & - & - & 036 & 611 & 14 \\
\hline SS-P-Water1-100 & - & - & - & 036 & 611 & 14 \\
\hline SS-P-Water1B-380 & - & - & - & 036 & 611 & 14 \\
\hline SS-P-PV3-380 & 2 Pre / 2 Post & 1 Pre & OTP partially plugged with debris, possibly teflon tape. & 036 & 613 & 16 \\
\hline SS-P-PV3-200 & - & - & Issue with data logger. & 036 & 614 & 17 \\
\hline SS-P-PV3-100 & 2 Pre / 2 Post & - & OTP partially plugged with debris, possibly teflon tape. & 036 & 615 & 18 \\
\hline SS-P-PV1-380 & 1 Pre / 1 Post & 1 Pre / 1 Post & - & 036 & 616 & 18 \\
\hline SS-P-PV1-200 & 1 Pre / 1 Post & 1 Pre / 2 Post & - & 036 & 617 & 20 \\
\hline SS-P-PV1-100 & 1 Pre / 1 Post & 2 Pre / 1 Post & 706 um had temporary plug. Re-opened. & 036 & 618 & 20 \\
\hline SS-P-S7-380 & 1 Pre & 1 Pre & - & 041 & 619 & 25 \\
\hline SS-P-S9-380 & - & - & - & 041 & 620 & 25 \\
\hline SS-P-TAR8-H2O3 & - & - & Orifice 1 is OTP $35 \mathrm{~T}$. & 041 & 621 & 29 \\
\hline SS-P-TAR8-H2O3B & - & - & Orifice 1 is OTP $35 \mathrm{~T}$. Repeat test. & 041 & 621 & 31 \\
\hline SS-P-S25-380 & 1 Pre / 1 Post & 1 Pre & 245 um OTP in position 4, rather than position 1. & 041 & 622 & 31 \\
\hline SS-P-S27-380 & 1 Pre / 1 Post & - & - & 041 & 623 & 36 \\
\hline SS-P-S31-380 & 1 Pre & 1 Pre & - & 041 & 624 & 38 \\
\hline SS-P-S33-380 & - & - & - & 041 & 625 & 38 \\
\hline SS-P-SAR20-H2O2 & - & - & - & 041 & 626 & 40 \\
\hline SS-P-S19-380 & 1 Pre & 1 Pre & 382 and 534 um plugged with debris. & 041 & 627 & 41 \\
\hline SS-P-S19-380-R1 & - & - & Repeat test. 245 um plugged with debris. & 041 & 627 & 43 \\
\hline SS-P-S19-380-R2 & - & - & Repeat test. No debris. & 041 & 627 & 44 \\
\hline SS-P-S19-200 & - & - & 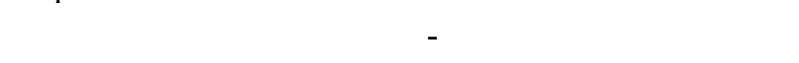 & 041 & 628 & 45 \\
\hline SS-P-STR8-H2O8 & - & - & - & 041 & 629 & 46 \\
\hline SS-P-SO48-380 & - & - & Dead-end test. Plugged in 15 seconds. & 041 & 630 & 48 \\
\hline SS-P-SO48-380-300 & - & - & Dead-end test. & 041 & 631 & 49 \\
\hline SS-P-SAR8-H2O1 & - & - & 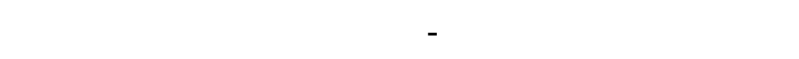 & 041 & 632 & 50 \\
\hline SS-P-S13-380 & 1 Pre / 1 Post & 1 Pre & - & 041 & 633 & 51 \\
\hline SS-P-S13-100 & 1 Pre / 1 Post & - & - & 041 & 634 & 52 \\
\hline
\end{tabular}




\section{Distribution}

No. of

Copies

\section{Local Distribution*}

$8 \quad$ Pacific Northwest National Laboratory

J Blanchard

K7-15

GN Brown

P7-25

PA Gauglitz

K7-15

ML Kimura

K6-28

DE Kurath

K6-24

LA Mahoney

K7-15

PP Schonewill

P7-25

Information Release (pdf)

Project File

K3-52

3 Bechtel National, Inc.

A Hassan

H4-02

S Omberg-Carro

H4-02

WTP R\&T Docs

H4-02

3 DOE-ORP

JS Fox

H6-60

CC Harrington

H6-60

DL Noyes

H6-60

*All distribution will be made electronically. 




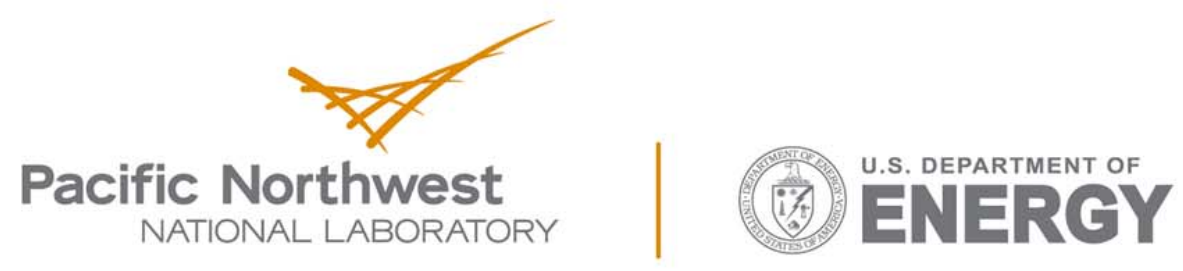

Proudly Operated by Battelle Since 1965

902 Battelle Boulevard

P.O. Box 999

Richland, WA 99352

1-888-375-PNNL (7665)

www.pnnl.gov 